\title{
STANDARD SUBSTANCES FOR THE CALIBRATION OF VISCOMETERS
}

\author{
By Eugene C. Bingham and Richard F. Jackson
}

\section{CONTENTS}

Page

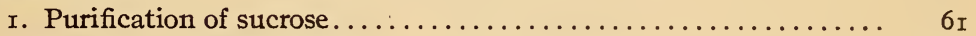

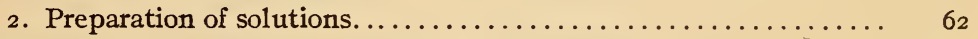

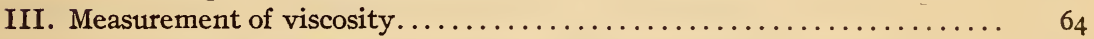

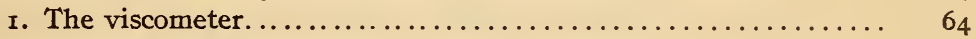

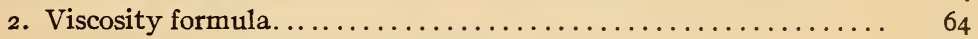

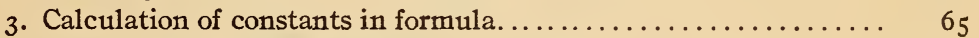

4. Calculation of the pressure..................... $6_{5}$

5. Details in regard to instrument and measurements.......... 69

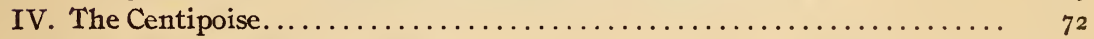

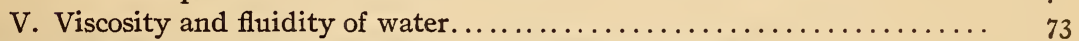

VI. Viscosity and fluidity of ethyl alcohol-water mixtures............ 76

VII. Viscosity of sucrose solutions. . . . . . . . . . . . . . . . . . . . 77

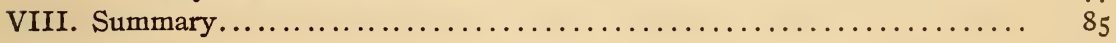

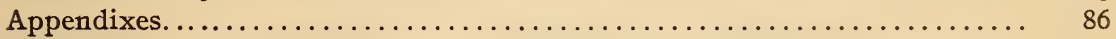

Appendix A.-Density in grams per milliliter of mixtures of ethyl alcohol

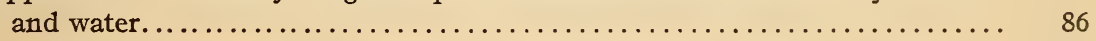

Appendix B.-Density in grams per milliliter of sucrose solutions......... 86

\section{INTRODUCTION}

In making measurements of viscosity in absolute units it is very desirable to have several substances available whose viscosities are accurately known in order that the accuracy of the method of measurement may be judged. Instruments whose results are expressed in terms of merely arbitrary numbers do not possess any advantage in this respect, since it is still necessary that the numbers obtained by two different instruments of the same type should agree, and in attaining this end the use of two or more substances of known viscosity is obviously of advantage.

Water is naturally the most important substance for this purpose since it can be so easily obtained in a pure condition and its viscosities at different temperatures have been very carefully 
determined. But water is ill-suited for the calibration of the short-capillary technical viscometer, since water is so very much more fluid than most oils for which these instruments were intended. In spite of the oft-repeated statement to the contrary, the viscosities of two substances are by no means directly proportional to the times of flow of equal volumes through a given capillary under the same head. The chief cause of this lack of proportionality is the fact that the energy is not all expended in overcoming viscous resistance, a part of it being used up in imparting kinetic energy to the fluid entering the capillary. Thus in the flow of water through an Engler instrument only about io per cent ${ }^{1}$ of the total energy expended is used in overcoming viscous resistance, the remaining 90 per cent being used in imparting kinetic energy to the liquid. The presence of so large a kinetic energy correction renders it manifestly desirable to have at hand some substance of high viscosity which can easily be obtained in a pure condition and whose viscosity is accurately known.

Castor oil and olive oil have been studied, but it has not been determined to what extent the viscosity may vary with the conditions of manufacture and exposure to light and air.

No pure hydrocarbon is readily available which possesses sufficiently high molecular weight. Monoacid alcohols of high molecular weight, like amyl alcohol, are not cheaply and easily obtained in the pure and anhydrous condition. A mixture of 45 per cent by volume of ethyl alcohol and water has a viscosity which is almost exactly four times that of water at $0^{\circ} \mathrm{C}$. Since the viscosity of ethyl alcohol-water mixtures passes through a maximum for this concentration, the viscosity does not change rapidly with the concentration, which is a marked advantage. The viscosities of alcohol and water mixtures have been determined with care by several observers.

When more viscous substances are desired, the poly-acid alcohols are available, and of these glycerol is perhaps the best for the purpose. It is, however, hygroscopic and not readily obtainable in the pure anhydrous condition so that the preparation of a solution of predetermined concentration offers some difficulty.

The sugars are valuable substances for the purpose. They are not hygroscopic; they are crystallizable so that they may easily be obtained in a very pure condition. The concentration of sucrose

\footnotetext{
1 Obtained by substituting the dimensions given in Ubbelohde's Tabellen zum Englerschen Viskosimeter, p. 24 , in our equation (2) assuming the viscosity of water at $20^{\circ}$ to be 0.0 roos and the time of flow to be $5 \mathrm{I}$ seconds.
} 
solutions may be determined by direct weighing of the constituents or from the density of the solution, or by means of the polariscope. Sucrose is very soluble in water, so that its solutions offer a wide range of viscosities. There is no concentration of sucrose in water which possesses the advantage of the alcoholic solution noted above, whose viscosity is independent of the exact concentration; hence it is necessary to guard the sucrose solutions against evaporation. Fortunately the technique of handling sucrose solutions has already been carefully worked out. ${ }^{2}$

The viscosity of sucrose solutions has repeatedly been the object of study, but the recent discovery ${ }^{3}$ of important sources of error in viscosity measurement which have hitherto remained undetected makes it desirable that these solutions be the object of still further research. Fortunately the data for water are sufficiently complete so that the more important corrections thus far recognized can all be made with sufficient certainty for our present purposes.

\section{SUCROSE SOLUTIONS}

\section{PURIFICATION OF SUCROSE}

The sucrose used in preparing the solutions was purified by crystallization from aqueous solution in the manner previously described by Bates and Jackson. ${ }^{4}$ Their procedure in outline was as follows: The material, a quantity of good granulated cane sugar of commerce, was dissolved in an equal weight of distilled water, clarified with a small quantity of washed "alumina cream," filtered and boiled in vacuo at a temperature of about $35^{\circ} \mathrm{C}$ until a concentration of 80 per cent was reached. The supersaturated sirup was seeded with a few crystals of sucrose and allowed to crystallize while in continuous motion. The crystals were separated from the mother liquor in a powerful centrifugal machine and were washed with aqueous alcohol. The crystallization was repeated until no evidence of impurity could be obtained.

The progress of the purification was studied and is described in the paper referred to. They found that sucrose prepared by this method contained less than 0.002 per cent of ash. The reducing substances, aside from sucrose itself, were of the order of 0.00 I per cent if present at all. The optical rotary power of the material remained unchanged after fractional crystallization from aqueous

2 This Bulletin, 10, p. 537; 1914.

${ }^{8} \mathrm{~J}$. Am. Chem. Soc., 38, p. 27 ; 1916.

4 This Bulletin, 13, p. 75, 1916; Scientific PaperNo. 268. 
solution and after precipitation with ethyl and methyl alcohol. The specific rotation of the substance in the concentration of the normal ${ }^{5}$ solution was found for $\lambda=5892.5$ A to be $66: 529$, or slightly higher than the mean of the measurements of Tollens and of Nasini and Villavecchia who found for it $66^{\circ} 502 .{ }^{6}$ The sugar used in the present investigation was prepared from the same source and possessed the same rotary power as that prepared by Bates and Jackson.

\section{PREPARATION OF SOLUTIONS}

In preparing the solutions for the viscosity measurements the constituents were weighed into a flask and the sugar dissolved. The solution in general was not completely free from dust particles. The amount of dust was too small to be weighable, but by accumulation in the capillary of the viscometer could readily have affected the time of flow. The solution was consequently poured on filters of hardened filter paper and repeatedly poured back to remove shreds acquired from the paper. The clear solution was finally poured through a funnel into a calibrated volumetric flask.

Three measurements of the concentrations of the solutions were made, two of which depended upon the solution density and one upon the rotary power.

The volumetric flasks which were used possessed graduated necks about $6 \mathrm{~mm}$ inside diameter. The graduations were ro in number $0.02 \mathrm{ml}$ apart. The interval between successive marks could be estimated to one-tenth of one division. The original solution was poured into the flask to some point on the scale, and flask and solution immersed in the water of a thermostat. When sufficient time had elapsed for the solution to assume the temperature of $20: 00$, its volume was observed. From these data the density of the solution was calculated. Then by comparison with the tables of the Kaiserliche Normal Eichungs Kommission, the per cent composition of the solution was obtained.

The second measurement, made after the sample for viscometer measurement was taken, consisted of determining the density of the approximately normal solution taken for polarization. A portion of the original solution was poured into another weighed volumetric flask, and flask and solution weighed. Enough of the solution was taken to correspond to about $26 \mathrm{~g}$ of sucrose in 100

T The normal concentration is $26 \mathrm{~g}$ in $100 \mathrm{ml}$ of solution in accordance with the usage in sugar analysis.

This Bulletin, 13, p. 125; 19r6. 
$\mathrm{ml}$. The sides of the flask were rinsed down into the solution and the latter diluted nearly to the capacity of the flask. The temperature was adjusted and the flask filled to the mark and weighed.

The third measurement consisted of a polarization of the approximately normal solution on a quartz-wedge saccharimeter. The thoroughly mixed solution was poured into polariscope tubes of known length and polarized at a fixed temperature. The reading of the saccharimeter was controlled by comparison with quartz plates No. I and No. 3, which are the primary standards of this Bureau referred to and described in the paper by Bates and Jackson. In determining the sugar value of these plates the conversion factor $34: 620$ was used instead of the erroneous $34: 657$.

In addition to the solutions prepared from purified sucrose one was prepared from a quantity of good granulated sugar of commerce in order to determine whether or not this generally available material would be suitable for standardization of instruments of ordinary precision. The substance after filtration contained but 0.012 per cent of ash. Its concentration was determined from the density of the solution by the second method described above, from its polarization, and from the reading of a standardized hydrometer. Since the effect of the impurities upon the fluidity was problematical, no attempt was made to apply corrections for them. The mean value of the three determinations was taken for the concentration. It is apparent that a calibrated hydrometer gives a satisfactory determination of the concentration.

The summary of the analyses is given in Table $I$.

TABLE 1

Analytical Data on Sucrose Solutions

\begin{tabular}{|c|c|c|c|c|c|}
\hline \multirow[b]{2}{*}{ Solution } & \multicolumn{5}{|c|}{ Percentage concentration by weight in vacuo } \\
\hline & $\begin{array}{l}\text { By density } \\
\text { of original } \\
\text { solution }\end{array}$ & $\begin{array}{l}\text { By density } \\
\text { of solution } \\
\text { taken for } \\
\text { polarization }\end{array}$ & $\begin{array}{c}\text { By polari- } \\
\text { zation }\end{array}$ & $\begin{array}{l}\text { By stand- } \\
\text { ard hy- } \\
\text { drometer }\end{array}$ & Mean \\
\hline No. $1 .$. & 39.96 & 40.01 & 3999 & & 39. 99 \\
\hline No. $2 \ldots \ldots \ldots \ldots$. & 40.00 & 39.97 & 39.99 & & 39.99 \\
\hline No.3............ & 59.97 & 59.93 & 59.93 & & 59.94 \\
\hline No. $4 \ldots \ldots \ldots \ldots \ldots$. & 20.003 & ............ & 20.011 & & 20.007 \\
\hline No. 5 a........... & $\ldots$ & 60.15 & 60.12 & 60.24 & 60.17 \\
\hline
\end{tabular}




\section{MEASUREMENTS OF VISCOSITY}

\section{THE VISCOMETER}

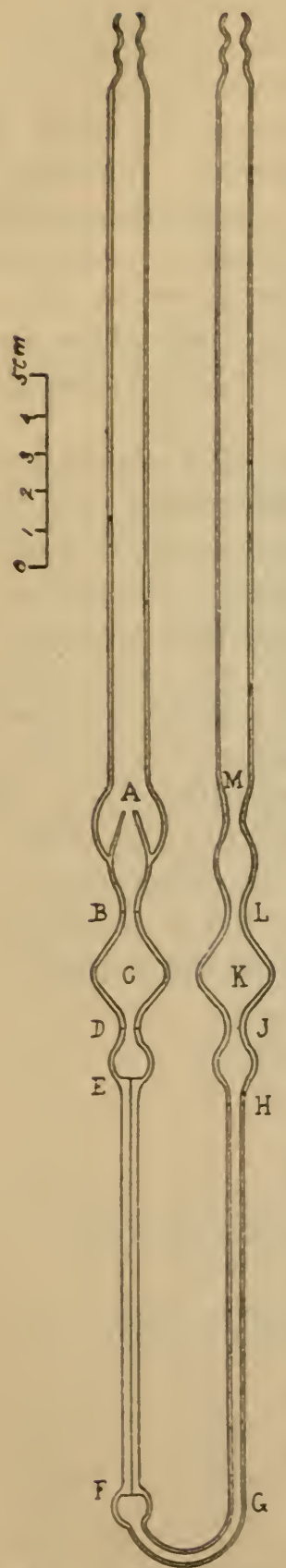

The viscometer used in this investigation is shown in Fig. I, drawn to scale. The method of making a measurement was as follows: The clean and dry instrument was filled from $H$ to $A$ with the liquid to be measured, the surplus liquid overflowing into the trap at $A$. The liquid was introduced by means of a pipette drawn out into a fine tube. The left limb was connected with a tank filled with air under a pressure which could be measured on a water manometer, the right limb already having been connected with the air. The time which the meniscus required in falling from $B$ to $D$ was taken as the time of flow. The liquid was then in position for an observation of the time of flow in the opposite direction. When the temperature was raised, the volume was again adjusted by causing the surplus to run over into the trap.

\section{VISCOSITY FORMULA}

Knowing the time of flow, $t$, the pressure, $p$, and the two constants of the instrument, $C$ and $C^{\prime}$, it became possible to calculate the viscosity, $\eta$, of the liquid for the temperature of observation, using the formula

$$
\eta=C p t-C^{\prime} \rho / t
$$

The value of the density, $\rho$, does not need to be accurately known, since it appears only in the term which represents the kinetic energy correction, which in our experiments was purposely kept small in order that the slight uncertainties in regard to the value of the correction term might be ren-

FIG. 1.-The isiscometer. dered neglible. 
The complete viscosity formula for the capillary tube method is

$$
\eta=\frac{\pi g r^{4} p t}{8 v(l+\lambda)}-\frac{m n \rho v}{8 \pi t(l+\lambda)}
$$

where $v$ is the volume of flow, $r$ is the radius, and $l$ the length of the capillary, $\lambda$ is a correction to be made to the length on account of viscous resistance outside of the capillary and to the distortion of the stream lines just within the entrance to the capillary. According to all of the evidence at hand this correction is negligible when the capillary is very long in comparison with the radius of the tube. The number of capillaries in series is represented by $n$, while $m$ is a constant whose value is being generally accepted to be about I.I $2 .^{7}$

\section{CALCULATION OF CONSTANTS IN FORMULA}

From the approximate dimensions $v=4.00$ and $l=7.50$ we can calculate the value of $C^{\prime}$

$$
C^{\prime}=\frac{m n V}{8 \pi l}=0.02376
$$

Observing the rate of flow of pure water at $20^{\circ} \mathrm{C}$ under a given pressure, and taking the absolute viscosity of water at this temperature to be 0.01005 , we may calculate the value of $C$

$$
C=\frac{\eta+C^{\prime} \rho / t}{p t}
$$

\section{CALCULATION OF THE PRESSURE}

The pressure used in the above formulas is expressed in grams per square centimeter. It is obtained as follows: If the height read on the manometer scale-corrected for scale error, if necessaryis $h_{0}$, Fig. 2, and the density of the liquid in the manometer is $\rho_{0}$, then the pressure is $h_{\mathrm{o}} \rho_{\mathrm{o}}$. But this pressure is subject to several corrections which may be small but must be taken into consideration. (I) The correction for buoyancy of the air is $-h_{\mathrm{o}} \rho$ air. The air in the closed limb of the manometer is under pressure and is therefore denser than the air outside. If the middle of the bulbs of the viscometer were at the level of the middle of the manometer the correction for this cause would amount to $-\frac{h_{\mathrm{o}}}{2} \rho_{\text {air }} \frac{h_{\mathrm{o}}}{1033}$. 
If, however, the middle point of the manometer is at a distance $h^{\prime}$ below the middle of the viscometer, there is a further correction

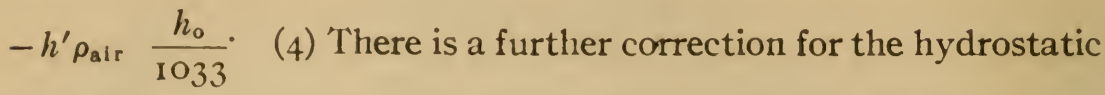
head within the viscometer, arising from the fact that it is impossible to construct an instrument in which the two bulbs are of exactly the same shape and size or at the same height. If the

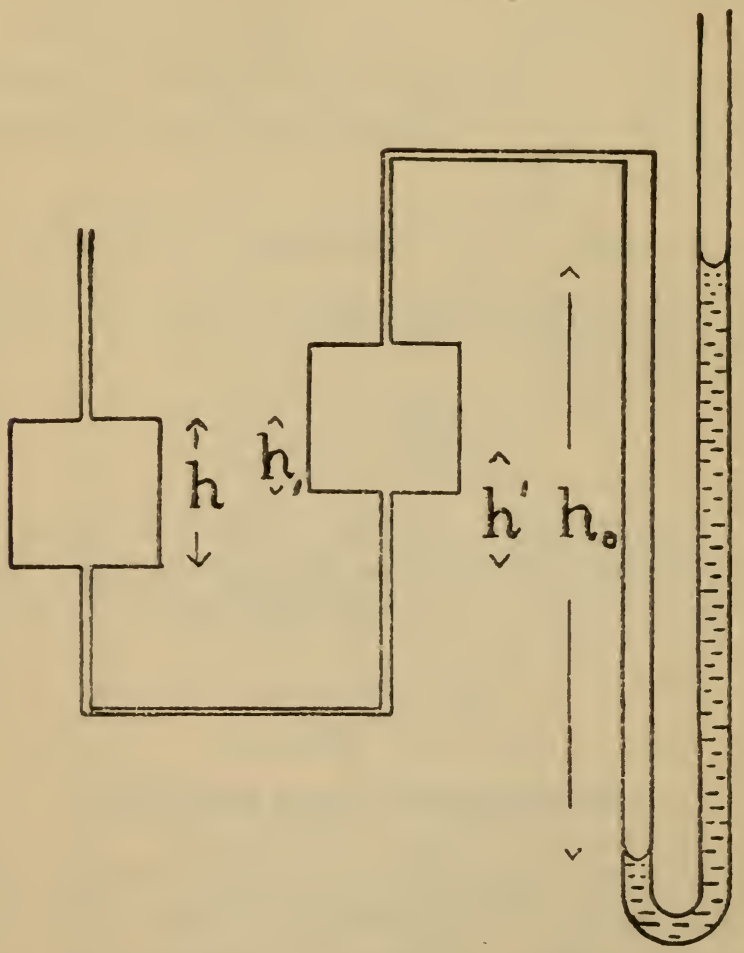

FIG. 2.-Diagram illustrating the method of estimating the pressure used in a viscosity determination.

hydrostatic head is $h_{1}$, Fig. 2, obtained as will be described later, the pressure correction will be $h_{1} \rho$ and this may be either negative or positive, dependent upon the limb to which the pressure is being admitted; that is, whether the left limb is emptying or filling.

Making these corrections we have for the assumed constant pressure

$$
p_{0}=h_{0} \rho_{0}-h_{\mathrm{o}} \rho_{\mathrm{air}}-\frac{h_{\mathrm{o}}^{2}}{2066} \rho_{\mathrm{air}} \pm h^{1} \rho_{\mathrm{air}} \frac{h_{\mathrm{o}}}{1033} \pm h_{1} \rho
$$


We have calculated Tables 2 and 3 which simplify the use of the above formula, and cause the formula to take the form

$$
p_{\mathrm{o}}=h_{\mathrm{o}} \pm h_{1} \rho-K \pm L
$$

In this formula $h_{\mathrm{o}}$ is the height in centimeters of the water column in the manometer, $h_{1}$ is the hydrostatic head, and $\rho$ the density of the liquid within the viscometer, $L$ is the correction for the difference of level between viscometer and manometer. This correction may usually be made negligible in the construction of the apparatus, but if necessary, the corrections corresponding to different values of $h^{\prime}$ and $h_{\mathrm{o}}$ may be obtained from Table 2. Table 3 contains the values of $K$, including the corrections for temperature, buoyancy, etc., for the different temperatures and pressures.

A single example will serve to show the method of using the tables. In our viscometer $L$ was negligible, but the hydrostatic head was $h_{1}=0.2 \mathrm{~cm}$, the right bulb of the viscometer being higher than the left, so that, for a 40 per cent sugar solution at $20^{\circ} \mathrm{C}$, $\rho=1.176$, and at a pressure read on the manometer of $h_{0}=269.5$ $\mathrm{cm}$ at $23^{\circ} \mathrm{C}$, the correction is $(0.77+0.22+0.03)+0.24=1.3 \mathrm{~cm}^{\circ}$ when the pressure is on the left limb, or $(0.77+0.22+0.03)-$ $0.24=0.8 \mathrm{~cm}$ when the pressure is on the right limb of the viscometer.

TABLE 2

Values of $\mathrm{L}$

\begin{tabular}{|c|c|c|c|}
\hline \multirow{2}{*}{$\mathbf{h}^{\prime}$ in centimeters } & \multicolumn{3}{|c|}{$h_{0}$ in centimeters } \\
\hline & 100 & 200 & 300 \\
\hline $50 \ldots \ldots \ldots$. & 0.01 & 0.01 & 0.02 \\
\hline $100 \ldots .$. & .01 & .03 & .04 \\
\hline $200 \ldots \ldots$ & .03 & .05 & .08 \\
\hline $300 \ldots$ & .04 & .08 & .11 \\
\hline
\end{tabular}

(5) The applied pressure $p_{0}$ is not necessarily the true average pressure to be used in the viscosity formula, hence a further correction may be necessary. Bingham, Schlesinger, and Coleman ${ }^{{ }^{\mathrm{a}}}$, have shown that if the bulbs of the viscometer were cylindrical in shape and of the height $h$, the true average pressure $p$, obtained by integration, would be

$$
p=\frac{0.8686 h \rho}{\log _{10} \frac{p_{0}+h \rho}{p_{0}-h \rho}},
$$

\footnotetext{
8 In obtaining (6) from (5) $K=h_{\mathrm{o}}-h_{\mathrm{o}} \rho_{\mathrm{o}}+h_{\mathrm{o}} \rho_{\mathrm{a} i r}+\frac{h_{\mathrm{O}}^{2} \rho_{\mathrm{a}} \text { ir }}{2066}$

'The figures within the parenthesis are the interpolated value of . $K$

9. J. Amer. Chem. Soc., 37, p. 27; 1916.
} 
but the difference between $p$ and $p_{0}$ becomes less than 0.05 per cent - that is, negligible for ordinary purposes-when the value of $p_{0}$ becomes as great as 30 times that of $h \rho$. They have shown how to obtain the value of $h$ when this correction is not negligible and the bulbs of the viscometer are not true cylinders.

TABLE 3

Values of $\mathbf{K}$

\begin{tabular}{|c|c|c|c|c|c|c|c|c|c|c|c|c|}
\hline \multirow{2}{*}{$\begin{array}{l}\text { Temperature, } \\
{ }^{\circ} \mathrm{C}\end{array}$} & \multicolumn{12}{|c|}{ Manometer reading, $\mathbf{b}_{0}$} \\
\hline & 10 & 20 & 30 & 40 & 50 & 60 & 70 & 80 & 90 & 100 & 200 & 300 \\
\hline 5. & 0.013 & 0.025 & 0.039 & 0.053 & 0.066 & 0.079 & 0.094 & 0.108 & 0.122 & 0.136 & 0.285 & 0.482 \\
\hline $10 .$. & .016 & .030 & .045 & .064 & .078 & .095 & .112 & .129 & .145 & .162 & .337 & .533 \\
\hline $11 .$. & .017 & .032 & .050 & .068 & .083 & .101 & .119 & .137 & .154 & .172 & .357 & .563 \\
\hline $12 .$. & .018 & .035 & .053 & .072 & .089 & .108 & .126 & .145 & .163 & .183 & .379 & .596 \\
\hline 13.. & .019 & .037 & .057 & $.0 \pi 7$ & .095 & .115 & .135 & .155 & .175 & .195 & .403 & .632 \\
\hline $14 .$. & .020 & .040 & .061 & .082 & .102 & .123 & .144 & .165 & .187 & .208 & .429 & .671 \\
\hline $15 .$. & .022 & .043 & .065 & .088 & .110 & .131 & .154 & .177 & 199 & .222 & .457 & .713 \\
\hline 16. & .023 & .046 & .070 & .094 & .118 & .140 & .165 & .189 & .212 & .238 & .439 & .761 \\
\hline $17 .$. & .025 & .049 & .075 & .101 & .126 & .150 & .176 & .203 & .228 & .255 & .523 & .812 \\
\hline 18. & .027 & .053 & .080 & .108 & .135 & .161 & .189 & .217 & .245 & .273 & .559 & .866 \\
\hline $19 .$. & .029 & .057 & .086 & .116 & .144 & .173 & .203 & .233 & .262 & .292 & .597 & .923 \\
\hline 20. & .031 & .060 & .092 & .124 & .154 & .185 & .217 & .249 & .280 & .312 & .637 & 983 \\
\hline 21. & .033 & .065 & .098 & .132 & .165 & 198 & .232 & .265 & 299 & .333 & .679 & 1.045 \\
\hline 22. & .035 & .069 & .105 & .141 & .176 & .211 & .247 & .282 & .319 & .355 & .723 & 1. 113 \\
\hline $23 .$. & .037 & .074 & .112 & .151 & .188 & .225 & .264 & .301 & .341 & .379 & .770 & 1. 184 \\
\hline $24 .$. & .040 & .079 & .119 & .160 & .200 & .240 & .281 & .321 & .363 & .403 & .819 & 1.256 \\
\hline 25. & .042 & .084 & .127 & .170 & .212 & .255 & .298 & .341 & .385 & .428 & .869 & 1.331 \\
\hline 26. & .045 & .089 & .135 & .181 & .225 & .270 & .316 & .362 & .408 & .454 & .921 & 1.409 \\
\hline $27 .$. & .048 & .094 & .143 & .191 & .239 & .286 & .335 & .383 & .432 & .481 & .975 & 1.490 \\
\hline $28 .$. & .050 & .100 & .151 & .202 & .253 & .303 & .355 & .405 & .458 & .509 & 1.031 & 1.574 \\
\hline 29. & .053 & .105 & .160 & .214 & .268 & .321 & .375 & .429 & .484 & .538 & 1.089 & 1.661 \\
\hline $30 .$. & .056 & .111 & .169 & .226 & .283 & .339 & .396 & .453 & .511 & .568 & 1.149 & 1.751 \\
\hline $31 .$. & .059 & .117 & .178 & .239 & .298 & .357 & .417 & .478 & .538 & .599 & 1.210 & 1.842 \\
\hline $32 .$. & .062 & .124 & .188 & .251 & .314 & .376 & .439 & .503 & .567 & .630 & 1. 273 & 1.937 \\
\hline 33.. & .066 & .130 & .197 & .264 & .330 & .395 & .462 & .529 & .595 & .662 & 1. 337 & 2.033 \\
\hline $34 \ldots$ & .059 & .137 & .207 & .277 & .346 & .415 & .485 & .555 & .625 & .695 & 1. 403 & 2. 132 \\
\hline
\end{tabular}

To obtain the hydrostatic head $h_{1}$, we determine the times of flow $t_{1}$ and $t_{2}$ for some substance, such as water at $20^{\circ} \mathrm{C}$, for the right and left limbs of the instrument, respectively, with a given pressure, which is $p_{1}$, corrected except for the hydrostatic head. We have the equations

$$
p_{1}+h_{1} \rho=\frac{\eta+C^{\prime} \rho / t_{1}}{C t_{1}}
$$

and

$$
p_{1}-h_{1} \rho=\frac{\eta+C^{\prime} \rho / t_{3}}{C t_{2}}
$$


hence

$$
h_{1}=\frac{\eta}{2 C \rho}\left(\frac{\mathrm{I}}{t_{1}}-\frac{\mathrm{I}}{t_{2}}\right)+\frac{C^{\prime}}{2 C}\left(\frac{\mathrm{I}}{t_{1}^{2}}-\frac{\mathrm{I}}{t_{2}^{2}}\right) .
$$

In obtaining $h_{1}$ it is sufficient to use the approximate value of $C$, obtained by using $p_{1}$ in place of $p$ in equation 4 .

\section{DETAILS IN REGARD TO INSTRUMENT AND MEASUREMENTS}

The bulbs of the viscometer were made as short as practicable in order that the difference between the applied pressure and the true average pressure might be a minimum. The distance between the marks $B$ and $D$ was $3.0 \mathrm{~cm}$.

The bulbs were made conical in shape in order to obtain the necessary volume while avoiding nearly horizontal surfaces which might cause faulty drainage. Drainage troubles were further obviated by having the part of the instrument directly above the point $B$ in Fig. I, similar in shape to the part above the point $D$. By always reading the volume of flow on the left limb, irrespective of whether the direction of flow is from left to right or vice versa, we measure the time of flow of the volume which the bulb $C$ delivers in the former case but of the capacity of the bulb in the latter case. Thus any differences in the viscosity calculated from the times of filling and emptying of this bulb may serve as a test of the completeness of the drainage. A further test can of course be made by making observations of the time of flow at different pressures..$^{10}$

The capillary tube was cut off squarely and sealed into the instrument so as to avoid a trumpet-shaped opening in order that there may be no doubt about the maximum value of the kinetic energy correction being applicable.

In order to prove that the corrections made are trustworthy, a series of observations were made on water at $25^{\circ} \mathrm{C}$, using a considerable range of pressures. Table 4 shows that the calculated viscosity is satisfactorily constant.

${ }^{10} \mathrm{By}$ using an instrument similar to the one described in this Bulletin, 12, Scientific Paper No. 278. p. 309 (r916), all possibility of error due to bad drainage can be obviated, but in the present investigation that type of instrument is far less convenient than the one adopted and fortunately its use is unnecessary. 


\section{TABLE 4}

Viscosity of Water at $25^{\circ} \mathrm{C} \mathrm{Calculated} \mathrm{from} \mathrm{the} \mathrm{Constants} \mathrm{Obtained} \mathrm{from} \mathrm{Observations}$ on the Rate of Flow of Water at $20^{\circ} \mathrm{C}$, Assuming the Viscosity at this Temperature to be $0.01005\left(C=0.00000014307\right.$ and $\left.C^{\prime}=0.02376\right)$

\begin{tabular}{|c|c|c|c|c|c|c|c|c|c|}
\hline Limb & $t$ & p & $\mathbf{P}$ & $\eta$ & Limb & $t$ & D & $\mathbf{P}$ & $\eta$ \\
\hline & Secs. & $\mathrm{g} / \mathrm{cm}^{2}$ & $\mathrm{~g} / \mathrm{cm}^{2}$ & & & Secs. & $\mathrm{g} / \mathrm{cm}^{2}$ & $\mathrm{~g} / \mathrm{cm}^{2}$ & \\
\hline $\mathbf{R}$. & 570.9 & 110.04 & 109. 53 & 0.008946 & $\mathbf{R}$. & 399.6 & 157.59 & 156. 56 & 0.008951 \\
\hline L... & 572.9 & 109.65 & 109.14 & .008946 & L.. & 400.2 & 157.22 & 156.19 & .008943 \\
\hline R. . & 570.6 & 110.04 & 109.53 & .008942 & R. . & 306.5 & 205.43 & 203.67 & .008931 \\
\hline L... & 572.9 & 109.65 & 109.14 & .008946 & L... & 307.6 & 205.04 & 203. 28 & .008946 \\
\hline $\mathbf{R}$. & 571.3 & 110.04 & 109.53 & .008952 & $\mathbf{R}$. & 306.5 & 205.44 & 203.68 & .008932 \\
\hline L.... & 572.4 & 109.65 & 109. 14 & .008938 & L. . & 308.1 & 205.05 & 203.29 & .008961 \\
\hline R... & 819.2 & 76. 76 & 76. 51 & .008968 & R. . & 274.8 & 229.64 & 227.45 & .008943 \\
\hline L... & 821.2 & 76.37 & 76.12 & .008944 & L... & 276.8 & 228.08 & 225.92 & .008947 \\
\hline R.. & 818.2 & 76.81 & 76.56 & .008963 & $\mathbf{R}$. & 274.4 & 229.48 & 227.29 & .008923 \\
\hline L... & 820.6 & 76.42 & 76.17 & .008943 & L... & 274.8 & 229.58 & 227.39 & .008940 \\
\hline R. . & 399.4 & 157.56 & 156.53 & .008944 & R... & 273.4 & 230.45 & 228.24 & .008928 \\
\hline L... & 400.6 & 157.19 & 156.16 & .008950 & L.... & 275.1 & 229.72 & 227.53 & .008955 \\
\hline
\end{tabular}

In the above table, as well as in succeeding tables, we have given not merely the true average pressure $p$, but also the part of this pressure $P$, which is used up solely in overcoming viscous resistance. It is calculated by means of the formula

whence we have that

$$
\eta=C p t-C^{\prime} \rho / t=C P t
$$

$$
P=p-\frac{C^{\prime} \rho}{C t^{2}}
$$

The object in recording both $p$ and $P$ is in order to afford a measure of the kinetic energy correction.

The viscometer was attached to a brass frame which fitted in grooves on the side of the bath shown in Fig. 3, so that the viscometer was necessarily always in the same position. A part of the viscometer always projected above the bath, so that any vapor rising from the solution would tend to condense and run back. It may be remarked that the experiment was tried of repeating a measurement after heating a solution for several hours and then cooling, but without noteworthy effect.

The temperature was read by means of a telescope to one onehundredth of a degree centigrade. As the thermometer had been calibrated at the Reichsanstalt, it was unnecessary to redetermine its corrections, but its ice point was determined before and after the investigation. At the two highest temperatures used a part of the stem of the thermometer was exposed, for which a correction was also made. 


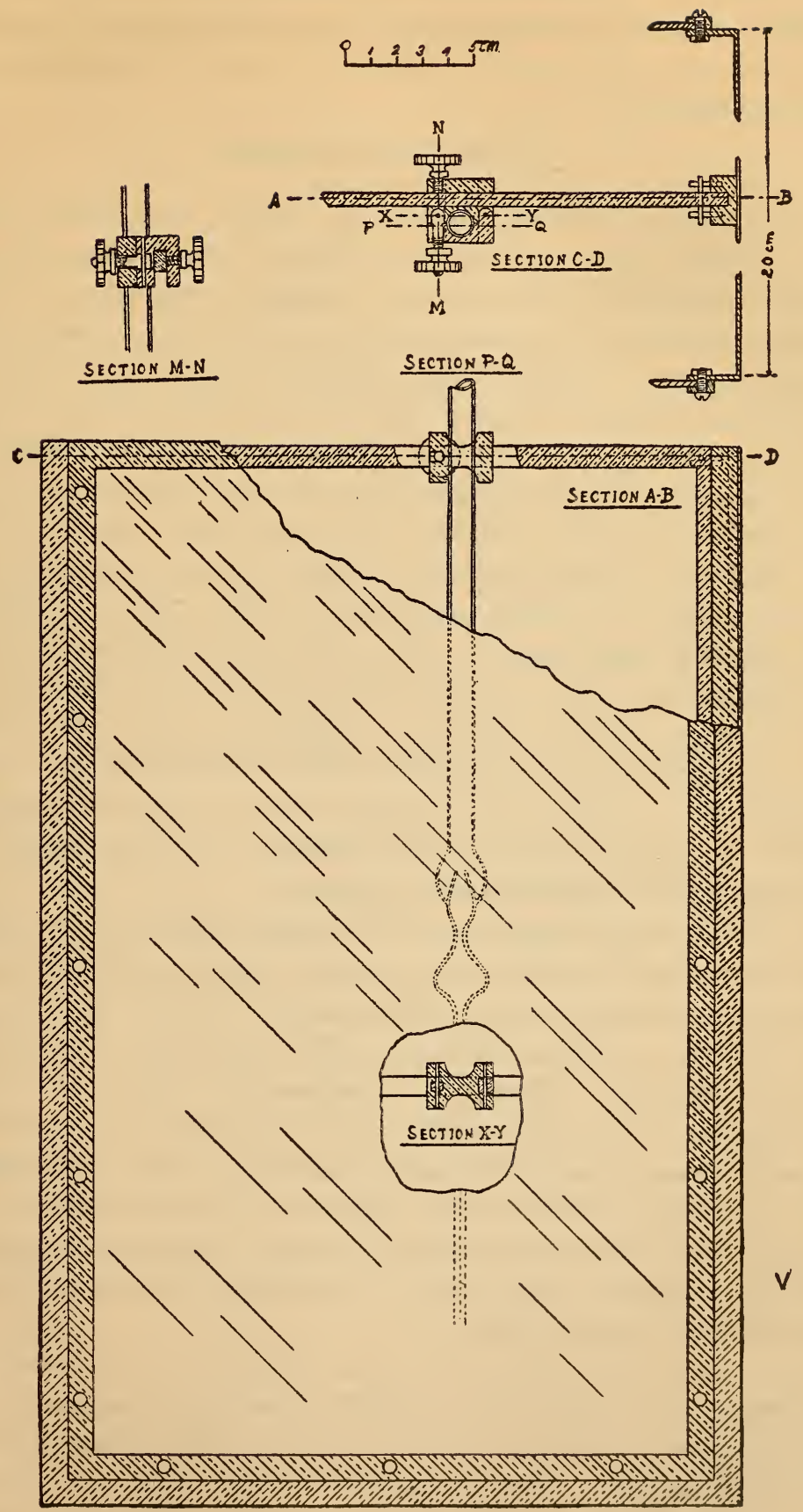

FIG. 3.-Detail of bath and frame with viscometer in position 
The time was measured on an Agassiz stop watch which had been tested by this Bureau and given a rating of 56.2 in class A. ${ }^{11}$ It was losing at the rate of a minute in a month during the time of the experiments.

\section{THE CENTIPOISE}

It has been common practice to record viscosities in other than absolute units. There are at least three reasons for using specific viscosities rather than absolute viscosities. Absolute viscosities are often inconveniently small fractions, necessitating the use of many ciphers. We naturally compare the viscosity of any liquid with that of water, which is usually used as the standard, hence the specific viscosity makes an immediate impression upon the mind which the absolute viscosity does not until after considerable practice. Finally, the so-called specific viscosities are often arbitrary numbers which are not reducible, or at least not easily reducible, to absolute units. Thus in the use of most technical instruments such as those of Engler and Saybolt, the so-called viscosities are recorded in terms of arbitrary numbers known as Engler degrees or Saybolt seconds, respectively. These numbers are far from being proportional to the absolute viscosity, and the absolute viscosity is not in any way calculable without a supplementary determination of the density, the determination of which is often omitted.

It is quite evident that in studying the relation of viscosity to other properties it is the true absolute viscosity that is desired. This is the strongest possible argument in favor of giving up the use of purely arbitrary numbers and expressing all results in absolute measure. Moreover, whether the specific viscosities are reducible to absolute units or not it is awkward to make comparison between specific viscosities based upon different standards. Thus, when one worker uses water at $0^{\circ} \mathrm{C}$ as his standard it is not easy to compare his work with that of another worker who used as a standard water at $25^{\circ} \mathrm{C}$, or either of these with results expressed in absolute units.

When two liquids having the same viscosity as measured on one instrument are measured in a different type of viscometer it has often been noted that the two liquids have quite different apparent specific viscosities. This arises from the fact that, in calculating the specific viscosity, important corrections are not taken into account which affect the two instruments differently. Thus, it is 
an objection to the use of specific viscosities that it has heretofore encouraged slovenly thinking in regard to the subject of viscosity measurement.

These views as to the relative merits of specific or absolute units are not as irreconcilable as may seem at first. It can probably be agreed that all viscosity measurements should be made under conditions such that the results can be expressed in absolute units. It is further desirable that, if specific viscosities be used, the same substance be taken as standard by all and that the absolute viscosity of the standard be definitely agreed upon, just as there is general agreement in the acceptance of atomic weights. If the suggestion of Deeley and Parr ${ }^{12}$ is accepted, and the absolute cgs unit of viscosity be known as the "poise," then it is convenient to use the submultiple of this unit, which is one-hundredth as large, and which may therefore properly be called the centipoise (cp). It so happens that the centipoise is almost exactly the viscosity of water at $20^{\circ} \mathrm{C}$, hence viscosities expressed as centipoises have the added advantage of being at the same time the specific viscosity of the substance referred to water as standard at almost exactly $20^{\circ} \mathrm{C}$.

\section{VISCOSITY AND FLUIDITY OF WATER}

Previous determinations of the absolute viscosity of water and other substances have neglected to take into account the possible difference between the mean applied pressure and the true average pressure. It has therefore seemed desirable to go over the data available and make the correction where necessary and practicable.

Thorpe and Rodger ${ }^{13}$ calculated their viscosities on the assumption that $m=\mathrm{I} .00$ instead of the more generally accepted value ${ }^{14}$ $m=$ I.I2. They also calculated the viscosity of water from the observations of Poiseuille, ${ }^{15}$ Sprung, ${ }^{16}$ and Slotte ${ }^{17}$ on the same assumption, hence it has seemed desirable to go over this data and make the needed correction. The error in the true average pressure and the error in the value of $m$ are both in the same direction, both tending to make the substance appear to be more viscous than it really is. In a few instances the error amounts to as much as 0.3 per cent.

In arriving at the most probable values for the viscosity of water, it is important to observe that Poiseuille is usually credited

12 Phil. Mag. [6], 26, p. 85; 1913.

13 Phil. Trans., 185A, p. 397; 8894 .

14 See p. 65.

${ }^{15} \mathrm{Mem}$. present. par divers Savants a l'academie Roy. des Sciences de l'Inst. de France, 9, p. 433: 1846.

16 Pogg. Ann., 159, p. ז; $x 876$.

17 Wied. Ann., 20, p. $257 ; 188_{3}$. 
with one series of observations from $0^{\circ}$ to $45^{\circ}$, whereas he actually made observations over this range of temperatures with four different capillaries, and as there is no reason for supposing that his observations were any less accurate than were those of his successors, we have recalculated his data entire.

Hosking ${ }^{18}$ does not give sufficient data to permit a recalculation to be made, but as he adjusted the values of $m$ and $\lambda$ in such a way as to get concordant values of viscosities at different pressures, it seems proper to include his values as they are recorded by him.

TABLE 5

Viscosity of Water in Centipoises as Determined by Different Observers

\begin{tabular}{|c|c|c|c|c|c|c|c|c|c|c|c|}
\hline \multirow{2}{*}{$\begin{array}{l}\text { Tempera- } \\
\text { ture, "C }\end{array}$} & \multicolumn{4}{|c|}{ Polseuilie } & \multirow{2}{*}{ Sprung } & \multirow{2}{*}{ Slotte } & \multirow{2}{*}{$\begin{array}{l}\text { Thorpe } \\
\text { and } \\
\text { Rod- } \\
\text { ger }\end{array}$} & \multirow{2}{*}{$\begin{array}{c}\text { Hosk - } \\
\text { ing }\end{array}$} & \multirow{2}{*}{$\begin{array}{l}\text { Bing- } \\
\text { ham } \\
\text { and } \\
\text { White }\end{array}$} & \multirow{2}{*}{$\begin{array}{l}\text { Aver- } \\
\text { age }\end{array}$} & \multirow{2}{*}{$\begin{array}{l}\text { Calcu- } \\
\text { lated by } \\
\text { tor- } \\
\text { mula }\end{array}$} \\
\hline & $A^{\circ}$ & C & $D^{\prime}$ & E & & & & & & & \\
\hline o.. & 1. 7755 & 1. 7900 & 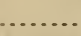 & 1. 7944 & 1.777 & 1.807 & 1. 7766 & 1. 7928 & 1.7960 & 1. 7887 & 1. 7921 \\
\hline $5 .$. & 1.5108 & 1. 5137 & 1.5143 & 1. 5142 & 1. 5089 & 1.523 & 1. 5083 & 1. 522 & 1.5241 & 1.5155 & 1. 5188 \\
\hline $10 .$. & 1. 3045 & 1.3078 & 1. 3088 & 1. 3088 & 1. 2995 & 1.313 & 1. 3014 & 1. 3105 & 1. 3002 & 1. 3061 & 1. 3077 \\
\hline $15 \ldots$ & 1. 1385 & 1.1464 & 1.1465 & 1.1456 & 1.1334 & 1. 143 & 1.1324 & 1. 142 & 1.1373 & 1. 1406 & 1. 1404 \\
\hline $20 \ldots$ & 1. 0028 & 1.0073 & 1.0063 & 1.0087 & .9978 & 1.007 & 1.0005 & 1.006 & 1.0054 & 1.0046 & 1. 0050 \\
\hline $25 \ldots$ & .8900 & .8964 & .8966 & .8973 & .8947 & .895 & .8900 & .8926 & .8940 & .8941 & .8937 \\
\hline $30 \ldots$ & .7958 & .8016 & .8011 & .8027 & .8183 & .802 & .7965 & .800 & .7991 & .8019 & .8007 \\
\hline $35 \ldots$ & .7154 & .7194 & .7190 & .7207 & .7216 & .723 & .7190 & .724 & .7223 & .7205 & .7225 \\
\hline $40 .$. & .6466 & .6523 & .6508 & .6531 & .6558 & .656 & .6525 & .657 & .6557 & .6533 & .6560 \\
\hline 45. & .5867 & .5934 & .5937 & .5932 & .6001 & .601 & .5959 & .600 & .5984 & .5958 & .5988 \\
\hline $50 .$. & & & & & .5512 & .552 & .5464 & .5500 & .5491 & .5497 & .5494 \\
\hline 55. & & & & & & .509 & .5044 & .508 & .5073 & .5072 & .5064 \\
\hline 60. & & & & & & .471 & .4676 & .469 & .4728 & .4701 & .4688 \\
\hline $65 \ldots$ & & & & & & .437 & .4343 & .436 & .4362 & .4359 & .4355 \\
\hline $70 .$. & & & & & & .407 & .4048 & .406 & .4069 & .4062 & .4061 \\
\hline $75 \ldots$ & & & & & & .380 & .3782 & .380 & .3794 & .3794 & .3799 \\
\hline $80 \ldots$ & & & & & & .356 & .3547 & .356 & .3558 & .3556 & .3565 \\
\hline $85 \ldots$ & & & & & & .334 & .3336 & .335 & .3337 & .3341 & .3355 \\
\hline $90 \ldots$ & & & & & & .315 & .3140 & .316 & .3133 & .3146 & .3165 \\
\hline $95 \ldots$ & & & & & & .297 & .2970 & .300 & .2983 & .2981 & .2994 \\
\hline 100. & & & & & & .281 & .2814 & .284 & & .2821 & .2838 \\
\hline
\end{tabular}

as. physik. Chem., 83, p. 641 ; 1913.

In next to the last column of Table 5 are given the averages of the values of the different observers. In the last column are given the values given by the formula

$$
t=A(\phi+D)+C-\frac{B}{\phi+D}
$$

which has been shown to be capable of expressing quite accurately the fluidity of liquids over a range of temperature, $A, B, C$, and $D$ being arbitrary constants, and $\phi$ being the fluidity in cgs units. We 
have taken $A=0.23275, B=8676.8, C=8.435$, and $D=\mathrm{I} 2 \mathrm{O}$. The calculated values are for the most part very close to the average observed values. This is particularly true between $5^{\circ}$ and $80^{\circ}$. It seems probable, therefore, that in taking $1.005 \mathrm{cp}$ as the viscosity of water at $20^{\circ} \mathrm{C}$ all of the figures are significant.

It is often desirable to know the viscosity of water at other than the 5-degree intervals given above, hence we have calculated the fluidity and viscosity of water for every degree between $0^{\circ}$ and $100^{\circ}$, using equation (I0) in the form

$$
\phi=2.1482\left\{(t-8.435)+\sqrt{8078.4+(t-8.435)^{2}}\right\}-\mathrm{I} 20
$$

TABLE 6

Fluidity and Viscosity of Water Calculated by Formula for Every Degree Between $0^{\circ}$ and $100^{\circ} \mathrm{C}$

\begin{tabular}{|c|c|c|c|c|c|c|c|c|}
\hline Temperature, & $\begin{array}{l}\text { Flu- } \\
\text { idity }\end{array}$ & $\begin{array}{l}\text { Vis- } \\
\text { cosity } \\
\text { in } \mathrm{cp}\end{array}$ & Temperature, & $\begin{array}{l}\text { Flu- } \\
\text { idity }\end{array}$ & $\begin{array}{l}\text { Vis- } \\
\text { cosity } \\
\text { in } C D\end{array}$ & Temperature, & $\begin{array}{l}\text { Flu- } \\
\text { idity }\end{array}$ & $\begin{array}{l}\text { Vis- } \\
\text { cosity } \\
\text { in } c p\end{array}$ \\
\hline 0. & 55.80 & 1. 7921 & 33. & 132.93 & 0.7523 & 67. & 236.25 & 0.4233 \\
\hline & 57.76 & 1.7313 & 34. & 135.66 & .7371 & 68. & 239.57 & . 4174 \\
\hline 2. & 59.78 & 1.6728 & 35. & 138.40 & .7225 & 69. & 242.91 & . 4117 \\
\hline 3.. & 61.76 & 1. 6191 & 36. & 141.15 & .7085 & $70 \ldots$ & 246.26 & .4061 \\
\hline 4.. & 63.80 & 1.5674 & $37 \ldots$ & 143.95 & .6947 & $71 \ldots$ & 249.63 & .4006 \\
\hline $5 .$. & 65.84 & 1. 5188 & 38. & 146.76 & .6814 & $72 \ldots$ & 253.02 & . 3952 \\
\hline $6 \ldots$ & 67.90 & 1.4728 & $39 .$. & 149.60 & .6685 & $73 \ldots$ & 256.42 & . 3900 \\
\hline $7 .$. & 70.01 & 1.4284 & 40. & 152.45 & .6560 & $74 \ldots$ & 259.82 & .3849 \\
\hline $8 .$. & 72.15 & 1. 3860 & $41 .$. & 155. 30 & .6439 & $75 \ldots$ & 263.25 & . 3799 \\
\hline $9 .$. & 74. 28 & 1.3462 & 42. & 158. 20 & .6321 & $76 \ldots$ & 266.67 & .3750 \\
\hline 10. & 76.47 & 1. 3077 & 43. & 161.11 & .6207 & 77. & 270.12 & . 3702 \\
\hline . & 78.66 & 1. 2713 & 44. & 164.02 & .6097 & 78. & 273.57 & .3655 \\
\hline 2. & 80.89 & 1. 2363 & 45. & 167.00 & .5988 & 79. & 277.04 & .3610 \\
\hline . & 83. 14 & 1. 2028 & 46. & 169.97 & .5883 & 80. & 280.53 & .3565 \\
\hline 14. & 85.40 & 1.1709 & 47. & 172.95 & .5782 & 81. & 284.03 & .3521 \\
\hline 5. & 87.69 & 1.1404 & 48. & 175.95 & .5683 & 82. & 287.53 & .3478 \\
\hline 16. & 90.00 & 1. 1111 & 49. & 178.95 & .5588 & 83. & 291.03 & . 3436 \\
\hline 17. & 92.35 & 1.0828 & 50. & 182.00 & .5494 & $84 \ldots$ & 294.54 & . 3395 \\
\hline 18. & 94.71 & 1.0559 & 51. & 185.05 & .5404 & 85. & 298.06 & .3355 \\
\hline $19 .$. & 97.10 & 1.0299 & 52. & 188.14 & . 5315 & $86 \ldots$ & 301.63 & . 3315 \\
\hline 20. & 99.50 & 1.0050 & 53. & 191.23 & .5229 & 87. & 305.21 & . 3276 \\
\hline 20.20 & 100.00 & 1.0000 & $54 .$. & 194.34 & .5146 & 88. & 308.78 & .3239 \\
\hline 21. & 101.94 & .9810 & 55. & 197.45 & .5064 & 89. & 312.35 & . 3202 \\
\hline $22 .$. & 104.40 & .9579 & 56. & 200.62 & . 4985 & $90 .$. & 315.92 & .3165 \\
\hline $23 .$. & 106. 86 & .9358 & 57. & 203.78 & .4907 & 91. & 319.53 & .3130 \\
\hline $24 .$. & 109. 38 & .9142 & $58 \ldots$ & 206.95 & .4832 & 92. & 323.13 & . 3095 \\
\hline $25 \ldots$ & 111.91 & .8937 & $59 \ldots$ & 210.13 & . 4759 & 93. & 326.74 & .3060 \\
\hline $26 \ldots$ & 114.45 & .8737 & $60 \ldots$ & 213. 33 & .4688 & $94 \ldots$ & 330.38 & .3027 \\
\hline $27 \ldots$ & 117.03 & .8545 & 61. & 216.54 & .4618 & $95 \ldots$ & 334.01 & .2994 \\
\hline $28 \ldots$ & 119.62 & .8360 & 62. & 219. 80 & .4550 & $96 .$. & 337.65 & . 2962 \\
\hline $29 .$. & 122. 25 & .8180 & 63. & 223. 07 & .4483 & $97 .$. & 341.30 & .2930 \\
\hline 30.. & 124.89 & .8007 & $64 \ldots$ & 226. 34 & .4418 & $98 .$. & 344.96 & . 2899 \\
\hline $31 .$. & 127.54 & .7840 & $65 \ldots$ & 229.64 & .4355 & $99 .$. & 348.63 & . 2868 \\
\hline 32. & 130.22 & .7679 & 66. & 232.94 & .4293 & 100. & 352.30 & . 2838 \\
\hline
\end{tabular}




\section{VISCOSITY AND FLUIDITY OF ETHYL ALCOHOL-WATER MIXTURES}

It was stated above that ethyl alcohol-water mixtures possess certain advantages for the purpose of testing viscometers. They have already been used successfully for this purpose by Winslow $\mathrm{H}$. Herschel, of this Bureau.

The fluidities of ethyl alcohol-water mixtures have already been determined by various observers, the data being brought together in a paper by Bingham, White, Thomas, and Cadwell. ${ }^{10}$ The older data is subject to some uncertainty on account of various circumstances, hence in getting the average some system of weighting seemed necessary. In obtaining the average values given in Tables 7 and $S$ the data of Bingham and Thomas ${ }^{19}$ was given a weight of three, that of Noack $^{20}$ of two, and that of Traube, ${ }^{21}$ Pagliani, and Batelli, ${ }^{22}$ and Stephan ${ }^{23}$ of one.

\section{TABLE 7}

Fluidity of Alcohol-Water Mixtures

\begin{tabular}{|c|c|c|c|c|c|c|c|c|c|c|c|c|c|}
\hline \multirow{4}{*}{$\begin{array}{c}\text { Tem- } \\
\text { perature, } \\
{ }^{\circ} \mathrm{C}\end{array}$} & \multicolumn{13}{|c|}{ Weight, percentage of ethyl aicohol } \\
\hline & 0 & 10 & 20 & 30 & 39 & 40 & 45 & 50 & 60 & 70 & 80 & 90 & 100 \\
\hline & \multicolumn{13}{|c|}{ Volume, percentage of ethyl alcohol at $25^{\circ} \mathrm{C}$} \\
\hline & 0 & 12.36 & 24.09 & 35.23 & 44.92 & 45.83 & 50.94 & 55.93 & 65.56 & 74.80 & 83.59 & 92.01 & 100 \\
\hline 0.. & 55.8 & 30.2 & 18.8 & 14.4 & 13.8 & 14.0 & 14.4 & 15. 2 & 17.4 & 21.0 & 27.1 & 36.6 & 56.4 \\
\hline 5. & 65.8 & 38.8 & 24.6 & 18.9 & 17.8 & 17.9 & 18. 2 & 19.0 & 21.6 & 25.6 & 32.0 & 43. 3 & 61.6 \\
\hline $10 .$. & 76.5 & 45.9 & 31.6 & 24.7 & 22.8 & 22.8 & 23.0 & 23.9 & 26. 5 & 30.6 & 36.9 & 47.6 & 68.2 \\
\hline 15. & 87.7 & 55.8 & 38.2 & 30.7 & 28.4 & 28.3 & 23.5 & 29.1 & 31.8 & 36.1 & 43.3 & 55.5 & 75.1 \\
\hline 20. & 99.5 & 65.0 & 45.8 & 36.9 & 34.7 & 34.4 & 34. 7 & 34.8 & 37.4 & 42.2 & 49.8 & 62.1 & 83.3 \\
\hline 25. & 111.9 & 75.6 & 55.1 & 45.9 & 42.5 & 42.5 & 41.9 & 41.7 & 44.6 & 49.1 & 57.2 & 70.2 & 91.2 \\
\hline $30 \ldots$ & 124.9 & 86. 2 & 64.4 & 53.4 & 50.0 & 49.4 & 49.5 & 49.6 & 51.9 & 56.6 & 65.3 & 78.2 & 99.7 \\
\hline 35. & 138.4 & 99.4 & 75.1 & 63.3 & 58.6 & 58.3 & 57.7 & 58.0 & 60.1 & 65.4 & 73.8 & 87.2 & 109.4 \\
\hline $40 .$. & 152.4 & 110.2 & 86.2 & 73.1 & 67.9 & 67.5 & 66.9 & 66.7 & 69.1 & 74.4 & 83.1 & 96.6 & 119.9 \\
\hline $45 .$. & 167.0 & 123. 2 & 98.5 & 84.1 & 77.9 & 77.6 & 76.5 & 77.3 & 78.7 & 84.1 & 92.5 & 106.5 & 130.8 \\
\hline so.. & 182.0 & 136. 3 & 110.2 & 95.2 & 89.0 & 88.3 & 87.1 & 86.6 & 88.7 & 94.2 & 103.3 & 117.9 & 142.5 \\
\hline 55. & 197.4 & 150.9 & 122.9 & 107.6 & 100.7 & 100.2 & 98.4 & 98.0 & 100.3 & 106.0 & 115.3 & 130.8 & 155.2 \\
\hline $60 \ldots$ & 213. 3 & 164.3 & 135.8 & 119.9 & 113.0 & 112.0 & 110.3 & 109.5 & 110.8 & 116.8 & 126.7 & 142.1 & 168. 9 \\
\hline $65 .$. & 229.6 & 180.5 & 150.1 & 133.0 & 125.3 & 124.7 & 122. 6 & 122.3 & 124. 1 & 130.6 & 140.7 & 156.0 & 181.5 \\
\hline 70. & 246.3 & 194.5 & 164.5 & 146.4 & 138.0 & 137.5 & 135.2 & 135.1 & 137.2 & 143.9 & 153.9 & 169.9 & 198.6 \\
\hline $75 \ldots$ & 263.2 & 210.2 & 178.8 & 160.3 & 151.5 & 150.8 & 148.9 & 148.7 & 150.8 & 157.1 & 166.6 & 183.0 & 212.5 \\
\hline $80 \ldots$ & 280.5 & 232.7 & 198.1 & 176.4 & 167.1 & 166. 5 & 164.1 & 163.5 & 165.7 & & & & - \\
\hline
\end{tabular}

19 Zs. physik. Chem., 83, p. 644; 1913.

:0 Wied. Ann., 27, p. 289; $1 \$ \$ 6$.

${ }^{21}$ Ber. d. deutsch. chem. Gesell, 19, p. $8 ; 1 ; 1886$.

2 Atti. d. R. Acc. di Torino, 20, p. 845; 1885.

2) Wien. Ber., 46 (2a), p. 495; 1862. 
TABLE 8

Viscosity in Centipoises of Alcohol-Water Mixtures

\begin{tabular}{|c|c|c|c|c|c|c|c|c|c|c|c|c|c|}
\hline \multirow{4}{*}{$\begin{array}{c}\text { Tem- } \\
\text { perature, } \\
{ }^{\circ} \mathrm{C}\end{array}$} & \multicolumn{13}{|c|}{ Weight, percentage of ethyl alcohol } \\
\hline & 0 & 10 & 20 & 30 & 39 & 40 & 45 & 50 & 60 & 70 & 80 & 90 & 100 \\
\hline & \multicolumn{13}{|c|}{ Volume, percentage of ethyl alcohol at $25^{\circ} \mathrm{C}$} \\
\hline & 0 & 12.36 & 24.09 & 35.23 & 44.92 & 45.83 & 50.94 & 55.93 & 65.56 & 74.80 & 83.59 & 92.01 & 100 \\
\hline & 1. 792 & 3. 311 & 5. 319 & 6.94 & 7.25 & 7.14 & 6.94 & 6.58 & 5.75 & 4.7.72 & 3.690 & 2.732 & 1.773 \\
\hline 5. & 1.519 & 2.577 & 4.065 & 5.29 & 5.62 & 5.59 & 5.50 & 5.26 & 4.63 & 3.906 & 3.125 & 2. 309 & 1.623 \\
\hline 10. & 1. 308 & 2. 179 & 3. 165 & 4.05 & 4.39 & 4.39 & 4.35 & 4. 18 & 3.77 & 3. 268 & 2.710 & 2. 101 & 1. 466 \\
\hline .. & 1.140 & 1. 792 & 2.618 & 3. 26 & 3.52 & 3.53 & 3.51 & 3.44 & 3. 14 & 2.770 & 2.309 & 1.802 & 1.332 \\
\hline .. & 1.005 & 1.538 & 2. 183 & 2.71 & 2.88 & 2.91 & 2.88 & 2.87 & 2.67 & 2.370 & 2.008 & 1.610 & 1.200 \\
\hline $25 .$. & .894 & 1. 323 & 1.815 & 2.18 & 2.35 & 2.35 & 2.39 & 2. 40 & 2. 24 & 2.037 & 1.748 & 1. 424 & 1.096 \\
\hline $30 .$. & .801 & 1. 160 & 1. 553 & 1.87 & 2.00 & 2.02 & 2.02 & 2.02 & 1.93 & 1.767 & 1. 531 & 1.279 & 1.003 \\
\hline $35 .$. & .722 & 1.006 & 1.332 & 1.58 & 1.71 & 1.72 & 1.73 & 1.72 & 1.66 & 1.529 & 1.355 & \begin{tabular}{|l|l} 
& 1.147
\end{tabular} & .914 \\
\hline $40 .$. & .656 & .907 & 1.160 & 1. 368 & 1.473 & 1.482 & 1.495 & 1.499 & 1.447 & \begin{tabular}{|l|} 
\\
\end{tabular} & 1.203 & 1.035 & .834 \\
\hline 55. & .599 & .812 & 1.015 & 1. 189 & 1.284 & 1.289 & 1. 307 & 1. 294 & 1.271 & 1.189 & 1.081 & . 939 & .764 \\
\hline$\cdots$ & .549 & .734 & .907 & 1.050 & 1.124 & 1.132 & 1. 148 & 1.155 & 1.127 & 1. 062 & .968 & .848 & .702 \\
\hline $5 .$. & .507 & .663 & .814 & .929 & .993 & .998 & 1.016 & 1.020 & .997 & .943 & .867 & .764 & .644 \\
\hline ... & .469 & .609 & .736 & .834 & .885 & .893 & .907 & . 913 & .902 & .856 & .789 & .704 & .592 \\
\hline $65 .$. & .436 & .554 & .666 & .752 & .798 & .802 & .816 & .818 & .806 & .766 & .711 & .641 & .551 \\
\hline $70 .$. & .406 & .514 & .608 & .683 & .725 & .727 & .740 & .740 & .729 & .695 & .650 & .589 & .504 \\
\hline $75 .$. & .380 & .476 & .559 & .624 & .660 & . 663 & .672 & .672 & .663 & .636 & .600 & .546 & .471 \\
\hline $80 .$. & .356 & .430 & .505 & .567 & .598 & .601 & .609 & .612 & .604 & & & & \\
\hline
\end{tabular}

\section{VISCOSITY OF SUCROSE SOLUTIONS}

The first sucrose solution used was 39.99 per cent sucrose by weight in vacuo. The results obtained are given in Table 9 and plotted in Figs. 4 and 5. The first column shows whether the left or the right limb was emptying, the second column gives the corrected time of flow in seconds, the third column gives the corrected pressure, while the fourth column gives the pressure used up in overcoming the viscous resistance, and the fifth column gives the fluidity calculated for the measured temperature given in the sixth column. In the last column the temperatures ${ }^{24}$ are calculated corresponding to these fluidities, using the formula

$$
t=(\varphi+20) 0.597-\frac{1438.6}{\varphi+20}+38.24
$$

The agreement between the observed and calculated values is good.

Were the fluidity concentration curves linear they would follow the dotted lines. That the observed curves depart so

24 The temperatures are calculated instead of fluidities purely for the sake of convenience in the use of the formula. 


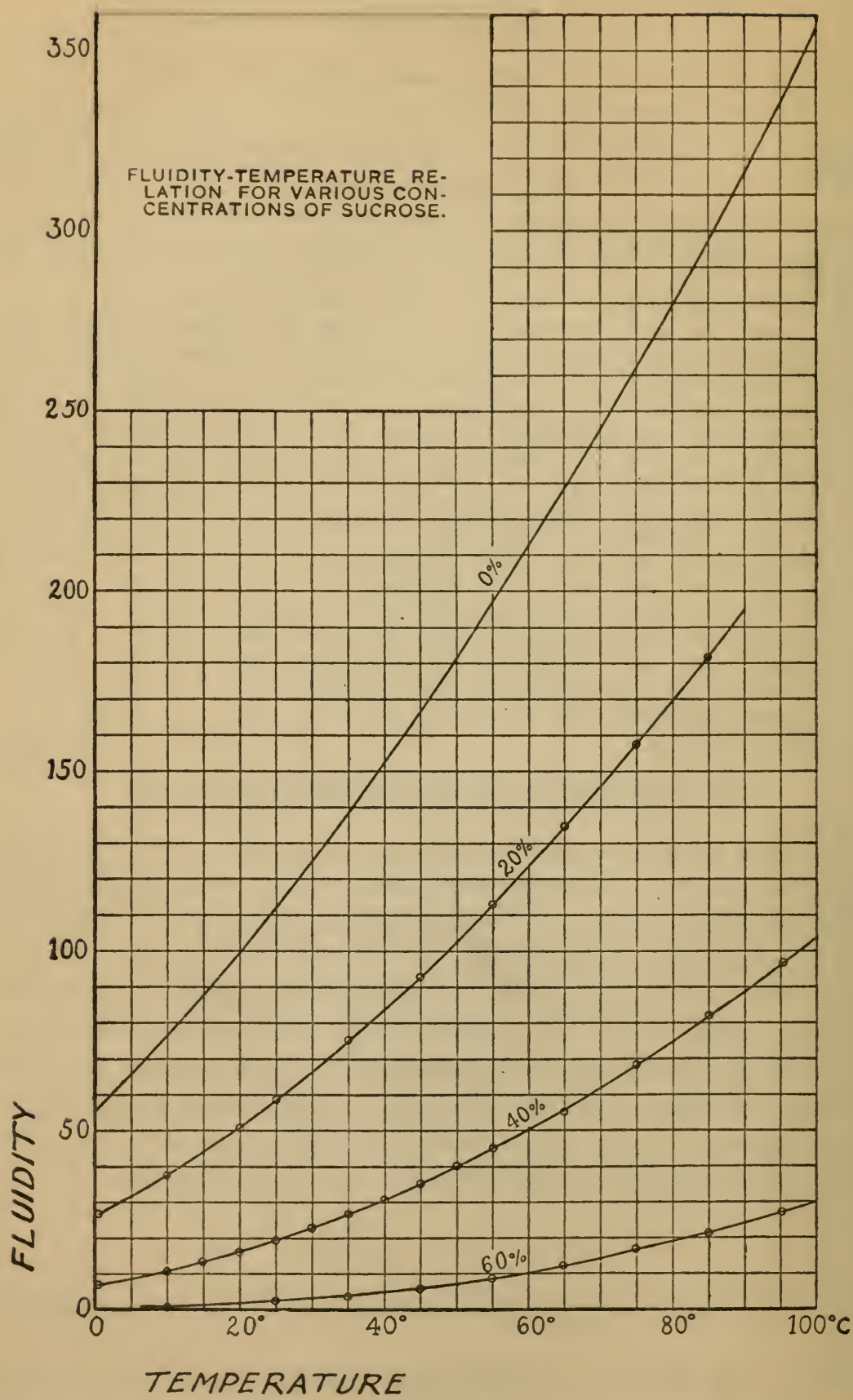

FIG. 4.-Showing the relation between fluidity and temperature for solutions of various sucrose content 
widely from the linear is an indication of the chemical hydration of the sugar.

TABLE 9

Fluidity of a 39.99 Per Cent Sucrose Solution at Various Temperatures

\begin{tabular}{|c|c|c|c|c|c|c|}
\hline Limb & Time, $t$ & $\begin{array}{c}\text { Pressure, } \\
\mathbf{p}\end{array}$ & $\underset{\mathbf{P}}{\text { Pressure, }}$ & $\begin{array}{c}\text { Fluidity } \\
\varphi\end{array}$ & $\begin{array}{l}\text { Tempera- } \\
\text { ture } \\
\text { measured }\end{array}$ & $\begin{array}{l}\text { Tempera- } \\
\text { ture } \\
\text { calculated }\end{array}$ \\
\hline & Seconds & & & & ${ }^{\circ} \mathrm{C}$ & ${ }^{\circ} \mathrm{C}$ \\
\hline L... & $3,487.8$ & 290.65 & 290.65 & 6.89 & 0.32 & 0.81 \\
\hline $\mathbf{R} \ldots$ & $3,437.1$ & 292. 97 & 292. 97 & 6.94 & .46 & .94 \\
\hline L... & $2,236.4$ & 289. 15 & 289. 11 & 10.81 & 9. 96 & 9. 94 \\
\hline $\mathbf{R} \ldots \ldots \ldots$ & $2,199.7$ & 293.43 & 293. 39 & 10.83 & 9.96 & 9.98 \\
\hline L.... & $1,486.7$ & 291.94 & 291.85 & 16.11 & 19. 98 & 19. 96 \\
\hline R.......... & $1,477.8$ & 293. 19 & 293. 10 & 16.14 & 19.98 & 20.00 \\
\hline L...... & $1,266.1$ & 286.44 & 286. 32 & 19. 28 & 24.99 & 25.07 \\
\hline $\mathbf{R} \ldots \ldots \ldots$ & $1,250.4$ & 289.92 & 289. 80 & 19.29 & 24.99 & 25.08 \\
\hline L... & 918.1 & 286. 39 & 286.16 & 26. 58 & 35.00 & 35.17 \\
\hline $\mathbf{R} .$. & 908.4 & 289.24 & 289.01 & 26.60 & 35.00 & 35.19 \\
\hline L....... & 730.6 & 288.74 & 288.40 & 35.09 & 45.00 & 44.92 \\
\hline $\mathbf{R} \ldots \ldots$ & 747.3 & 289.17 & 288. 83 & 35.21 & 45.00 & 45.14 \\
\hline L....... & 543.3 & 283. 34 & 282. 71 & 45.09 & 54.99 & 55.00 \\
\hline $\mathbf{R} \ldots \ldots \ldots$ & 545.8 & 284. 76 & 284.13 & 45.07 & 54.99 & 54.98 \\
\hline L........ & 437.1 & 284. 33 & 283. 34 & 56.18 & 64.96 & 64.83 \\
\hline $\mathbf{R}$... & 437.3 & 285.07 & 284.08 & 56.26 & 64.96 & 64.91 \\
\hline L... & 363.7 & 282.29 & 280.85 & 68.43 & 74.94 & 74.76 \\
\hline $\mathbf{R} .$. & 363.2 & 283. 14 & 281.70 & 68.32 & 74.94 & 74.69 \\
\hline L....... & 306.3 & 280.13 & 278. 11 & 82.05 & 85.03 & 85.39 \\
\hline $\mathbf{R} \ldots$ & 307.3 & 279.58 & 277.56 & 81.95 & 85.03 & 84.99 \\
\hline L.......... & 257.8 & 282.76 & 279.93 & 96.86 & 95.30 & 95.69 \\
\hline $\mathbf{R} \ldots \ldots \ldots$ & 257.2 & 283. 08 & 280.25 & 96.97 & 95.30 & 95.77 \\
\hline
\end{tabular}

The values of the fluidity given above do not agree with the values obtained by other observers, as will be shown later, hence the viscometer was tested with pure water and another series of measurements were made with an entirely new solution, which, however, happened to have the same concentration as the former, viz, 39.99 per cent by weight.

TABLE 10

Fluidity of a Second 39.99 Per Cent Sucrose Solution at Various Temperatures

\begin{tabular}{|c|c|c|c|c|c|c|}
\hline Limb & Time, $t$ & $\begin{array}{c}\text { Pressure, } \\
\text { p }\end{array}$ & $\underset{\mathbf{P}}{\text { Pressure, }}$ & $\begin{array}{c}\text { Fluidity } \\
\varphi\end{array}$ & $\begin{array}{l}\text { Tempera- } \\
\text { ture } \\
\text { observed }\end{array}$ & $\begin{array}{c}\text { Tempera- } \\
\text { ture } \\
\text { calculated }\end{array}$ \\
\hline & Seconds & & & & ${ }^{\circ} \mathrm{C}$ & ${ }^{\circ} \mathrm{C}$ \\
\hline L.. & $2,024.4$ & 257.97 & 257. 92 & 13. 39 & 14. 97 & 15. 10 \\
\hline L............ & $1,256.4$ & 288. 16 & 288.04 & 19. 31 & 24.99 & 25.12 \\
\hline $\mathbf{R}$... & $1,232.4$ & 293.15 & 293.02 & 19. 36 & 24. 99 & 25.18 \\
\hline L...... & $1,045.3$ & 293. 24 & 293.04 & 22.82 & 30.00 & 30.10 \\
\hline $\mathbf{R}$.. & $1,039.8$ & 294.43 & 294.27 & 22.84 & 30.00 & 30.24 \\
\hline L..... & 770.6 & 295.00 & 294.65 & 30.78 & 40.00 & 40.23 \\
\hline $\mathbf{R} \ldots \ldots$ & 768.4 & 295.41 & 295.10 & 30.82 & 40.00 & 40.27 \\
\hline L............. & 594.0 & 294. 30 & 293.73 & 40.06 & 50.00 & 50.14 \\
\hline $\mathbf{R} \ldots \ldots \ldots \ldots$ & 593.1 & 294.63 & 294. 10 & 40.07 & 50.00 & 50. 15 \\
\hline
\end{tabular}


The second sample gave values which correspond very well with the former values, hence we have additional reason for confidence in the reliability of our values. It should be noted in this connection that Bingham, Schlesinger, and A. B. Coleman, ${ }^{25}$ using a viscometer of different construction, have already noted that the observations of Hosking on sugar solutions may be in error. This was confirmed by the measurements of C. Coleman. ${ }^{25}$

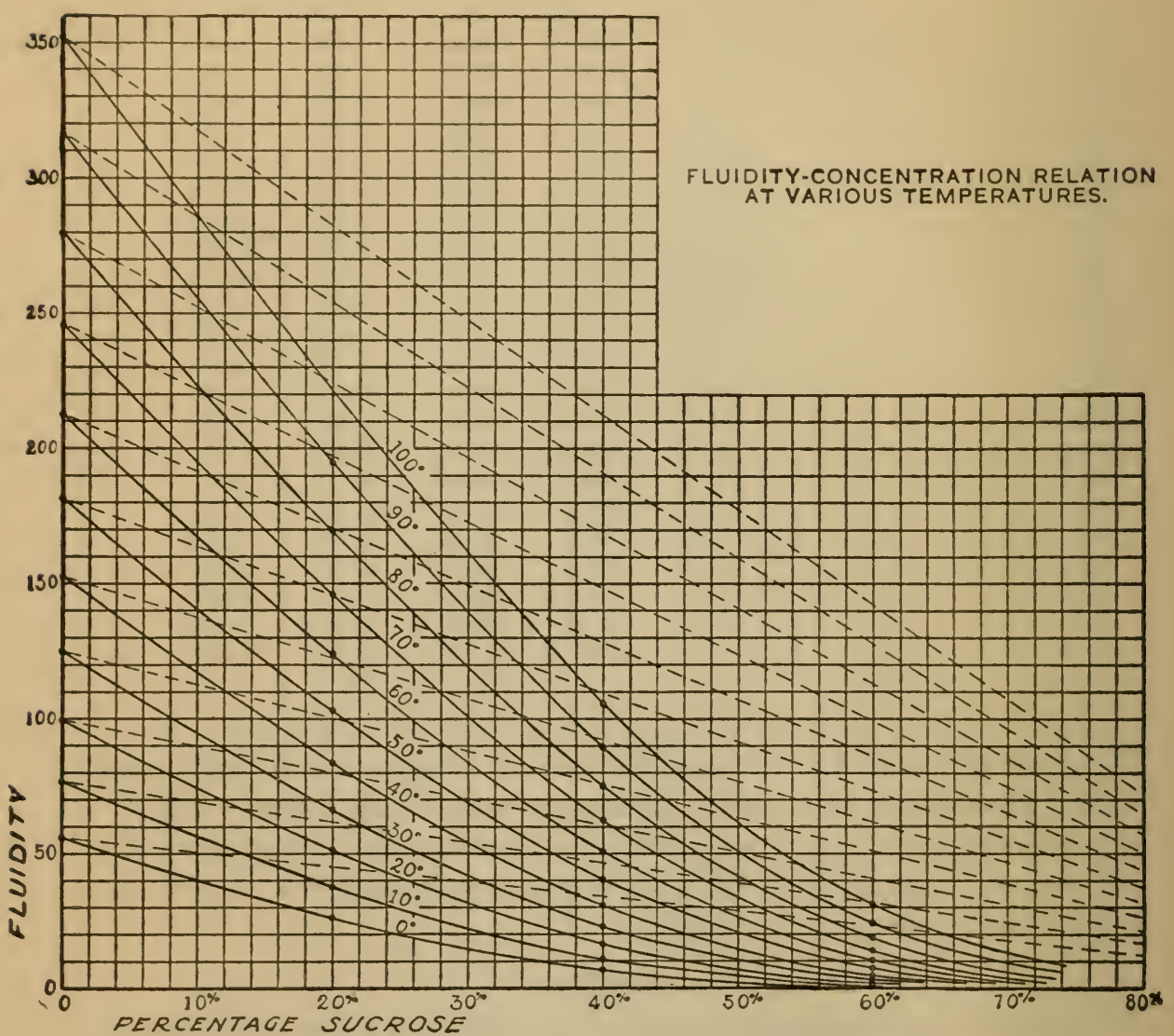

F1G. 5.-Showing relation between fluidity and sucrose content at various tem peratures

Having found an appreciable difference between our own values and those of other observers, it seemed desirable to measure the fluidity of a 20 per cent solution, the concentration actually obtained being 20.007 per cent. The fluidities are given in Table I I. The last observation recorded in the table was made several hours after the preceding observation, when the solution had cooled down from the high temperature. The fluidities are again considerably smaller than the values found by Hosking. 
TABLE 11

Fluidity of a 20.007 Per Cent Sucrose Solution at Various Temperatures

\begin{tabular}{|c|c|c|c|c|c|}
\hline Limb & Time, $t$ & Pressure, & $\underset{\mathbf{P}}{\text { Pressure, }}$ & $\underset{\varphi}{\text { Fluidity, }}$ & $\begin{array}{l}\text { Tempera- } \\
\text { ture }\end{array}$ \\
\hline & Seconds & & & & ${ }^{\circ} \mathrm{C}$ \\
\hline $\mathbf{L} \ldots$ & 899.1 & 290.43 & 290.21 & 26. 79 & 0.44 \\
\hline $\mathbf{R} \ldots .$. & 897.0 & 290.86 & 290.64 & 26.81 & .44 \\
\hline I....... & 643.4 & 289.26 & 288.83 & 37.61 & 9.96 \\
\hline $\mathbf{R} \ldots \ldots \ldots \ldots$ & 644.2 & 288. 77 & 288.34 & 37.63 & 9.96 \\
\hline $\mathbf{L} \ldots \ldots \ldots \ldots$ & 414. 7 & 288.42 & 287.38 & 58.65 & 24.99 \\
\hline R............. & 415.5 & 287.77 & 286.73 & 58.67 & 24.99 \\
\hline $\mathbf{L} \ldots \ldots \ldots \ldots$ & 263.4 & 288.91 & 286. 35 & 75.10 & 35.00 \\
\hline R............... & 261.4 & 288.89 & 286.29 & 75.09 & 35.00 \\
\hline L. $\ldots \ldots \ldots \ldots \ldots$ & 324.5 & 288.52 & 286.82 & …......... & 45.00 \\
\hline $\mathbf{R}, \ldots \ldots \ldots \ldots$ & 324.3 & 288.71 & 287.01 & 93.40 & 45.00 \\
\hline L............... & 217.8 & 287.93 & 284.20 & 112.92 & 54.99 \\
\hline $\mathbf{R} \ldots \ldots \ldots \ldots$ & 215.8 & 289.86 & 286.06 & 113.22 & 54.99 \\
\hline $\mathbf{L} \ldots \ldots \ldots \ldots \ldots$ & 201.3 & 262.51 & 258. 17 & 134.50 & 64.96 \\
\hline $\mathbf{R} \ldots \ldots \ldots \ldots$ & 200.5 & 262.86 & 258.48 & 134.89 & 64.96 \\
\hline $\mathbf{L} \ldots \ldots \ldots \ldots \ldots$ & 213.1 & 212.40 & 208.55 & 157.28 & 74.94 \\
\hline R........... & 212.4 & 212.84 & 208. 96 & 157.48 & 74.94 \\
\hline $\mathbf{L} \ldots \ldots \ldots \ldots \ldots \ldots$ & 248.4 & 157.68 & 154. 86 & 181. 72 & 85.03 \\
\hline $\mathbf{R} \ldots \ldots \ldots \ldots \ldots \ldots \ldots$ & 247.4 & 158.13 & 155.29 & 181.93 & 85.03 \\
\hline 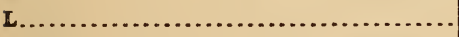 & $1,783.8$ & 76. 92 & 76.86 & 50.98 & 19. 98 \\
\hline
\end{tabular}

Table I 2 contains the results of measurements of the fluidity of a solution which contained 59.94 per cent sucrose by weight. This concentration has not been measured over a range of temperatures by previous observers.

TABLE 12

Fluidity of a 59.94 Per Cent Sucrose Solution at Various Temperatures

\begin{tabular}{|c|c|c|c|c|c|c|}
\hline $\operatorname{Limb}$ & Time, $t$ & $\begin{array}{l}\text { Pres- } \\
\text { sure, } p\end{array}$ & $\begin{array}{c}\text { Pres- } \\
\text { sure, } P\end{array}$ & $\underset{\varphi}{\text { Fluidity, }}$ & $\begin{array}{c}\text { Tem- } \\
\text { perature } \\
\text { observed }\end{array}$ & $\begin{array}{c}\text { Tem- } \\
\text { perature } \\
\text { calculated }\end{array}$ \\
\hline & Seconds & & & & ${ }^{\circ} \mathrm{C}$ & ${ }^{\circ} \mathrm{C}$ \\
\hline L. & 26,023 & 295.87 & 295.87 & 0.908 & 9.96 & 11.61 \\
\hline $\mathbf{R} \ldots \ldots \ldots \ldots$ & 10,310 & 296.61 & 296.61 & 2.286 & 24.99 & 24.99 \\
\hline L.... & 6,222 & 295.76 & 295.75 & 3. 798 & 35.00 & 34.84 \\
\hline $\mathbf{R} \ldots \ldots \ldots$ & 4,029 & 295.50 & 295.49 & 5. 871 & 45.00 & 44.90 \\
\hline L... & $2,736.6$ & 295.89 & 295.86 & 8.633 & 54.99 & 54.99 \\
\hline $\mathbf{R} \ldots$ & $1,957.2$ & 296.22 & 296.17 & 12.058 & 64.96 & 64.79 \\
\hline $\mathbf{L} \ldots$ & $1,392.0$ & 295.67 & 295.56 & [16.989] & 74.94 & 76. 30 \\
\hline $\mathbf{R} \ldots$ & $1,111.3$ & 295.65 & 295.48 & 21.286 & 85.03 & 85.03 \\
\hline L. . & 870.6 & 295.84 & 295. 57 & 27. 162 & 95.30 & 95.92 \\
\hline $\mathbf{L} \ldots \ldots \ldots \ldots$ & $1,508.4$ & 289.45 & 289. 34 & 16. 015 & 74.94 & 74. 18 \\
\hline
\end{tabular}

On calculating out the above data it was seen that the measurement at $74.94^{\circ}$ was manifestly in error, hence the last observation in the table was made on the same solution two days later, it 
having remained at room temperature in the meantime. The temperatures in the last column were calculated by means of the formula

$$
T=(\varphi+5) 1.472=\frac{323.2}{\varphi+5}+53.62
$$

It was easy to keep the solution at a temperature which was constant within one-tenth of a degree, hence the formula does not serve to reproduce the observed values satisfactorily. We may add that in so viscous a solution the fluidity is greatly affected by the temperature, a rise of $\mathrm{I}^{\circ}$ at $45^{\circ}$ causing an increase of 4.1 per cent in the fluidity.

A 60 per cent solution was now prepared from commercial sugar in order to learn whether any serious error would be made in using commercial sugar instead of specially prepared sugar. The solution proved to be 60.1 7 per cent sucrose. The fluidity is given in Table 13 .

\section{TABLE 13}

Fluidity of a $60.17 \mathrm{Par}$ Cent Solution of Commercial Sugar at $74.94^{\circ} \mathrm{C}$

\begin{tabular}{|c|c|c|c|c|c|}
\hline Limb & Time, $t$ & $\begin{array}{c}\text { Pres- } \\
\text { sure, p }\end{array}$ & $\begin{array}{c}\text { Pres- } \\
\text { sure, } P\end{array}$ & $\underset{\varphi}{\text { Fluidity }}$ & $\begin{array}{c}\text { Tem- } \\
\text { peraturs } \\
\text { observed }\end{array}$ \\
\hline L. & $\begin{array}{r}\text { Seconds } \\
1,484.6\end{array}$ & 292.91 & 292.80 & 16.08 & $\begin{array}{l}{ }^{\circ} \mathrm{C} \\
74.94\end{array}$ \\
\hline
\end{tabular}

For convenience in comparison the observed fluidities were plotted to a large scale and interpolated for even concentrations and for every $5^{\circ}$. The resulting fluidities are given in Table 14 and the corresponding viscosities are given in Table 15 .

TABLE 14

Fluidities of Sucrose Solutions Containing 0, 20, 40, and 60 Per Cent Sucrose by Weight at Every $5^{\circ} \mathrm{C}$ (Interpolated)

\begin{tabular}{|c|c|c|c|c|c|c|c|c|c|}
\hline \multirow{2}{*}{$\begin{array}{l}\text { Temper- } \\
\text { ature, }{ }^{\circ} \mathrm{C}\end{array}$} & \multicolumn{4}{|c|}{ Percentage sucrose by weight } & \multirow{2}{*}{$\begin{array}{l}\text { Temper- } \\
\text { ature, }{ }^{\circ} \mathrm{C}\end{array}$} & \multicolumn{4}{|c|}{ Percentage sucrose by welght } \\
\hline & $0 a$ & 20 & 40 & 60 & & 0 & 20 & 40 & 60 \\
\hline $0 \ldots \ldots$. & 55.91 & 26. 29 & 6.77 & 0.42 & $55 \ldots$. & 197.16 & 113. 12 & 45. 06 & 8.57 \\
\hline $5 \ldots$ & 65.99 & 31.71 & 8.65 & .64 & $60 \ldots$ & 212. 72 & 123. 79 & 50.47 & 10. 17 \\
\hline $10 \ldots$ & 76.56 & 37.71 & 10.21 & .91 & $65 \ldots$. & 229.41 & 134.81 & 56.24 & 11.99 \\
\hline $15 \ldots$ & 87.67 & 44.11 & 13. 39 & 1.34 & $70 \ldots$ & 246.18 & 145.97 & 62.17 & 13. 93 \\
\hline $20 \ldots$ & 99.54 & 51.02 & 16.13 & 1.77 & $75 \ldots \ldots \ldots$ & 263.57 & 157.56 & 68.41 & 16. 12 \\
\hline $25 \ldots$ & 111.84 & 58.69 & 19.28 & 2.28 & $80 \ldots$ & 281.21 & 169.53 & 74.96 & 18. 51 \\
\hline $30 \ldots$ & 124.70 & 66.51 & 22.82 & 2.96 & $85 \ldots$ & 299.31 & 181.80 & 81.92 & 21. 14 \\
\hline $35 \ldots$ & 133.79 & 75.12 & 26.58 & 3. 77 & $90 \ldots$ & 317.87 & & 89.06 & 24. 07 \\
\hline $40 \ldots$ & 153.07 & 83.82 & 30.78 & 4. 70 & $95 \ldots \ldots$. & 335.46 & & 96.41 & 26. 85 \\
\hline $45 \ldots$ & 167.84 & 93.42 & 35.13 & 5.82 & $100 .$. & 354.49 & & 104.11 & 29.96 \\
\hline $50 \ldots \ldots$ & 181.92 & 103.07 & 40.05 & 7.14 & & & & & \\
\hline
\end{tabular}


TABLE 15

Viscosities in Centipoises of Sucrose Solutions Containing 0, 20, 40, and 60 Per Cent Sucrose by Weight at Every $5^{\circ} \mathrm{C}$ (Interpolated)

\begin{tabular}{|c|c|c|c|c|c|c|c|c|c|}
\hline \multirow{2}{*}{$\begin{array}{l}\text { Temper- } \\
\text { ature, }{ }^{\circ} \mathrm{C}\end{array}$} & \multicolumn{4}{|c|}{ Percentage sucrose by weight } & \multirow{2}{*}{$\begin{array}{l}\text { Temper- } \\
\text { ature, }{ }^{\circ} \mathrm{C}\end{array}$} & \multicolumn{4}{|c|}{ Percentage sucrose by weight } \\
\hline & $0 a$ & 20 & 40 & 60 & & 0 & 20 & 40 & 60 \\
\hline $0 .$. & 1. 789 & 3.804 & 14.77 & 238 & 55. & 0.507 & 0.884 & 2. 219 & 11.67 \\
\hline $5 \ldots$ & 1.516 & 3. 154 & 11.56 & 156 & 60. & .470 & .808 & 1.982 & 9.83 \\
\hline $10 .$. & 1.306 & 2.652 & 9. 794 & 109.8 & $65 \ldots$ & .436 & .742 & 1.778 & 8.34 \\
\hline 15.. & 1.141 & 2. 267 & 7. 468 & 74.6 & $70 \ldots$ & .406 & .685 & 1.608 & 7.15 \\
\hline $20 .$. & 1.005 & 1.960 & 6.200 & 56.5 & $75 \ldots$ & .379 & .635 & 1.462 & 6.20 \\
\hline 25. & .894 & 1.704 & 5.187 & 43.86 & $80 .$. & .356 & .590 & 1. 334 & 5.40 \\
\hline $30 .$. & .802 & 1.504 & 4. 382 & 33. 78 & $85 .$. & .334 & .550 & 1. 221 & 4.73 \\
\hline $35 .$. & .720 & 1. 331 & 3. 762 & 26.52 & $90 .$. & .315 & & 1. 123 & 4.15 \\
\hline $40 \ldots$. & .653 & 1. 193 & 3. 249 & 21.28 & $95 \ldots$ & .298 & & 1.037 & 3.72 \\
\hline $45 \ldots$ & .596 & 1.070 & 2. 847 & 17.18 & $100 .$. & .282 & & .960 & 3. 34 \\
\hline $50 \ldots \ldots \ldots$ & .550 & .970 & 2. 497 & 14.01 & & & & & \\
\hline
\end{tabular}

$a$ These are the average viscosities given in Table 5 .

We reproduce here for the sake of comparison the viscosities of sugar solutions obtained by Hosking, ${ }^{26}$ Table 16 , and by Powell, ${ }^{27}$ Table I 7. Burkhardt, ${ }^{28}$ Rudorf, ${ }^{29}$ Grüneisen, ${ }^{30}$ and Green ${ }^{31}$ have studied the viscosity of sugar solutions, but not over a range of temperatures. The viscosities determined by Hosking are generally considerably lower than our values, although it is to be noted that we agree with Hosking satisfactorily at the lowest temperature in the 40 per cent solution and at the highest temperature in the 20 per cent solution. The values of Powell, are, in general, intermediate between Hosking's values and our own, but agree better with the former. Bingham, Schlesinger, and Coleman obtained $\mathrm{r} .73 \mathrm{I} \mathrm{cp}$ for the viscosity of a 20 per cent sugar solution at $25^{\circ} \mathrm{C}$ using the Washburn viscometer. This is considerably higher than the present value.

26 Phil. Mag. [5], 49, p. 274; 1900.

27 Trans. (London) Chem. Soc., 105, p. I; 1914.

${ }^{28}$ Zs. Rübenzuckerind. 1874. Cf. Castell-Evans Physico-Chemical Tables, 2, p. 652 ; 191r.

${ }^{20}$ Zs. physik. Chem., 43, p. $28 \mathrm{I}$; 1903.

${ }^{90}$ Wiss. Abh. d. Phys.'-'Tech. Reichsanstalt, 4, p. 239; 1905.

${ }^{21}$ Trans. (London) Chem. Soc., 93, p. 2023; 1908. 
TABLE 16

Viscosity of Sucrose Solutions in Centipoises According to Hosking ${ }^{32}$

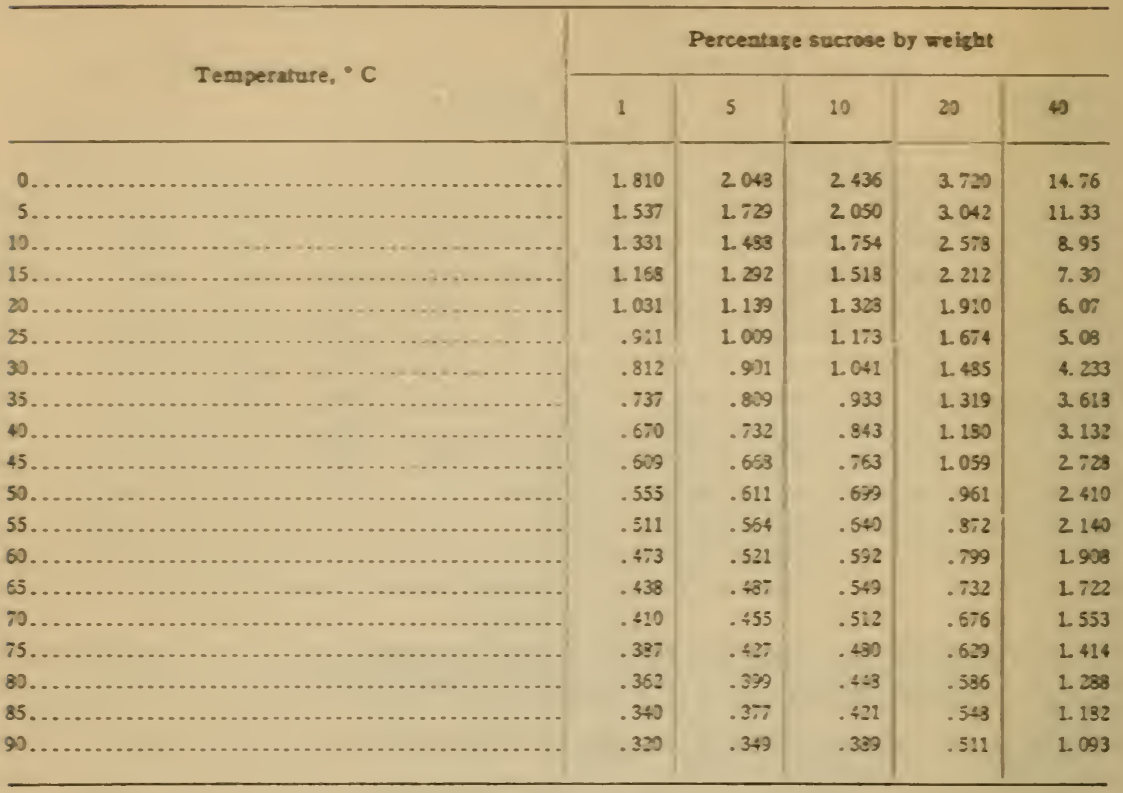

\section{TABLE 17}

Viscosity of Sucrose Solutions in Centipoises According to Powell 32

\begin{tabular}{|c|c|c|c|c|c|c|c|c|c|}
\hline \multirow{2}{*}{ Texperzture, " C } & \multicolumn{9}{|c|}{ Percentage sucrose by weight } \\
\hline & 1 & 5 & 10 & $: 5$ & 35 & 25 & 30 & 35 & 40 \\
\hline 25. & 2. 92 & $\therefore 0:$ & $\therefore 17$ & $\therefore .49$ & 1.70 & 211 & 275 & 3. 67 & $\leq 12$ \\
\hline 30.. &.$\$ 1$ & .30 & 1.05 & 2. 25 & 2. 50 & 1. 85 & 239 & 3. 14 & 4. 23 \\
\hline 35. & .73 & . ह0 & .94 & 1.10 & 1. 32 & 1. $5:$ & 205 & 2.73 & 3. 70 \\
\hline $40 .$. &.$\epsilon_{\bar{j}}$ & .72 & .84 & 1.00 & 1.15 & 1.43 & 1. 83 & 2.34 & 3.20 \\
\hline $45 \ldots$ & $.6 !$ & .55 & .76 & .90 & 1.06 & 1. 23 & 1.62 & 208 & 275 \\
\hline s).......... & .57 & $.5:$ & .70 & .50 & .95 & 1.15 & 1.4 & 1.85 & 240 \\
\hline
\end{tabular}

Same Solutions at $20^{\circ}$ According to Burkhardt

\begin{tabular}{|l|l|l|l|l|l}
\hline $20 \ldots \ldots \ldots \ldots \ldots \ldots$ & \\
\hline
\end{tabular}

From the data of Green ${ }^{32}$ we calculate the riscosity of a 40 per cent solution to be $6.08 \mathrm{cp}$ at $20^{\circ}$ and $5.066 \mathrm{cp}$ at $25^{\circ}$.

We have not attempted to apply any corrections to the abore data, but the probable corrections would tend to decrease the 
viscosity, hence they would not help to bring about agreement between our values and those of earlier observers.

In connection with the fact that our viscosities are in this case higher than those of most of our predecessors, it is of interest to note that when the viscosity of the commercial sugar solution used by us was reduced to the basis of a 60 per cent solution at $75^{\circ} \mathrm{C}$, we obtain $6.07 \mathrm{cp}$, which is also lower than the 6.20 obtained by us for specially purified sugar.

In the appendixes are given tables of densities of sucrose and ethyl-alcohol solutions, reproduced here for the convenience of any who may desire to use the data given in this paper for the purposes of calibration.

\section{SUMMARY}

I. For the purpose of the calibration of viscometers, there is need for one or more liquids whose viscosity is greater than that of water, which can be easily obtained, and whose viscosity is known with a considerable degree of certainty.

2. Of the suitable substances ethyl alcohol-water mixtures and sucrose solutions each possess certain marked advantages. The viscosities of the former are well known, there existing data by several observers which agree as well as can be expected; but the correctness of the data for the latter has been questioned. Hence we have redetermined the viscosity of a 20 and a 40 per cent solution by weight and have in addition measured the viscosity of a 60 per cent solution from $10^{\circ}$ to $95^{\circ} \mathrm{C}$. The viscosities obtained by us are generally somewhat higher than the values obtained hitherto, but we have every reason to believe that our values are worthy of confidence.

3. The existing data on the viscosity of water has been reviewed in order to correct it so far as possible according to our present knowledge. The viscosity and fluidity of water for every degree centigrade from o to roo has been calculated.

4. The advantages and disadvantages of expressing viscosity in absolute or specific units have been compared. The suggestion has been made that by expressing all data in terms of the centipoise (the one-hundredth part of the cgs unit), the absolute viscosity of substances would be practically also the specific viscosity, provided that we take water at $20^{\circ}$ as the standard. We find the most probable value for the viscosity of water at $20^{\circ} \mathrm{C}$ to be I.005 $\mathrm{cp}$.

Washington, August 8, rgir6. 


\section{APPENDIXES}

Appendix A.-Density in Grams per Milliliter of Mixtures of Ethyl Alcohol and Water ${ }^{33}$

\begin{tabular}{|c|c|c|c|c|c|c|c|}
\hline Per cent alcohol by weight & $10^{\circ} \mathrm{C}$ & $15^{\circ} \mathrm{C}$ & $20^{\circ} \mathrm{C}$ & $25^{\circ} \mathrm{C}$ & $30^{\circ} \mathrm{C}$ & $35^{\circ} \mathrm{C}$ & $40^{\circ} \mathrm{C}$ \\
\hline $0 \ldots$ & 0.99973 & 0.99913 & 0.99823 & 0.99708 & 0.99568 & 0.99406 & 0.99225 \\
\hline $5 .$. & 9098 & 9032 & 8938 & 8817 & 8670 & 8501 & 8311 \\
\hline $10 \ldots \ldots \ldots \ldots$ & 8393 & 8304 & 8187 & 8043 & 7875 & 7685 & 7475 \\
\hline $15 \ldots$ & 7800 & 7669 & 7514 & 7334 & 7133 & 6911 & 6670 \\
\hline $20 \ldots \ldots \ldots$ & 7252 & 7068 & 6864 & 6639 & 6395 & 6134 & 5856 \\
\hline $25 \ldots$ & 6665 & 6424 & 6168 & 5895 & 5607 & 5306 & 4991 \\
\hline $30 \ldots \ldots \ldots \ldots \ldots$ & 5977 & 5686 & 5382 & 5067 & 4741 & 4403 & 4055 \\
\hline $35 \ldots$ & 5162 & 4832 & 4494 & 4146 & 3790 & 3425 & 3051 \\
\hline $40 \ldots \ldots \ldots$ & 4238 & 3882 & 3518 & 3148 & 2770 & 2385 & 1992 \\
\hline $45 \ldots$ & 3226 & 2852 & 2472 & 2085 & 1692 & 1291 & 0884 \\
\hline $50 \ldots \ldots$ & 2162 & 1776 & 1384 & 0985 & 0580 & 0168 & .89750 \\
\hline $55 \ldots \ldots$ & 1055 & 0659 & 0258 & .89850 & .89437 & .89016 & 8589 \\
\hline $60 \ldots$ & .89927 & .89523 & .89113 & 8699 & 8278 & 7851 & 7417 \\
\hline $65 \ldots$ & 8774 & 8364 & 7948 & 7527 & 7100 & 6667 & 6227 \\
\hline $70 \ldots$ & 7602 & 7187 & 6766 & 6340 & 5908 & 5470 & 5025 \\
\hline $75 \ldots$ & 6408 & 5988 & 5564 & 5134 & 4698 & 4257 & 3809 \\
\hline $80 \ldots$. & 5197 & 4772 & 4344 & 3911 & 3473 & 3029 & 2578 \\
\hline $85 \ldots \ldots \ldots \ldots \ldots \ldots$ & 3951 & 3525 & 3095 & 2660 & 2220 & 1774 & 1322 \\
\hline $90 \ldots \ldots$ & 2654 & 2227 & 1797 & 1362 & 0922 & 0478 & 0028 \\
\hline $95 \ldots \ldots \ldots \ldots \ldots$ & 1278 & 0852 & 0424 & .79991 & .79555 & .79114 & .78670 \\
\hline $100 \ldots \ldots \ldots$ & .79784 & .79360 & .78934 & 8506 & 8075 & 7641 & 7203 \\
\hline
\end{tabular}

${ }^{33}$ This Bulletin, 9, p. 327 ; 1953.

Appendix B.-Density in Grams per Milliliter of Sucrose Solution ${ }^{34}$

\begin{tabular}{|c|c|c|c|c|c|c|c|c|c|}
\hline $\begin{array}{l}\text { Per cent } \\
\text { sucrose by } \\
\text { weight }\end{array}$ & $0^{\circ} \mathrm{C}$ & $10^{\circ} \mathrm{C}$ & $15^{\circ} \mathrm{C}$ & $20^{\circ} \mathrm{C}$ & $25^{\circ} \mathrm{C}$ & $30^{\circ} \mathrm{C}$ & $40^{\circ} \mathrm{C}$ & $50^{\circ} \mathrm{C}$ & $60^{\circ} \mathrm{C}$ \\
\hline $0 \ldots$ & 0.99987 & 0.99973 & 0.99913 & 0.99823 & 0.99707 & 0.99567 & 0.99232 & 0.98813 & 0.98330 \\
\hline $5 \ldots$ & 1.02033 & 1. 01960 & 1.01884 & 1.01784 & 1. 01661 & 1. 01518 & 1.01169 & 1.00735 & 1.00231 \\
\hline $10 \ldots$ & 4135 & 4016 & 3925 & 3813 & 3679 & 3530 & 3165 & 2720 & 2198 \\
\hline $15 \ldots$ & 6304 & 6146 & 6041 & 5916 & 5772 & 5612 & 5229 & 4772 & 4238 \\
\hline $20 .$. & 8546 & 8353 & 8233 & 8094 & 7940 & 7767 & 7366 & 6898 & 6358 \\
\hline $25 \ldots$ & 1. 10869 & 1. 10642 & 1. 10507 & 1. 10354 & 1. 10188 & 1. 10005 & 9585 & 9106 & 8563 \\
\hline $30 \ldots$ & 3274 & 3014 & 2863 & 2698 & 2517 & 2324 & 1. 11888 & 1. 11398 & 1. 10850 \\
\hline $35 \ldots$ & 5769 & 5473 & 5306 & 5127 & 4933 & 4730 & 4279 & 3779 & 3228 \\
\hline $40 \ldots$ & 8349 & 8020 & 7837 & 7648 & 7439 & 7214 & 6759 & 6248 & 5693 \\
\hline $45 \ldots$. & 1. 21018 & 1. 20657 & 1. 20460 & 1.20257 & 1. 20039 & 9812 & 9332 & 8811 & 8247 \\
\hline $50 \ldots$ & 3775 & 3382 & 3173 & 2958 & 2732 & 1.22495 & 1.21996 & 1.21465 & 1.20891 \\
\hline $55 \ldots$. & 6621 & 6203 & 5981 & 5753 & 5516 & 5271 & 4756 & 4211 & 3629 \\
\hline $60 \ldots$ & 9560 & 9117 & 8884 & 8644 & 8399 & 8144 & 7615 & 7058 & 6468 \\
\hline $65 \ldots . .$. & 1. 32591 & 1. 32125 & 1. 31882 & 1. 31631 & 1. 31376 & 1. 31113 & 1. 30571 & 1. 30002 & 9408 \\
\hline $70 \ldots$ & 5719 & 5230 & 4976 & 4716 & 4452 & 4181 & 3625 & 3047 & 1.32447 \\
\hline
\end{tabular}

is Plato, Abh. Norm. Eich.-Komm., 2, p. 140, 1900; Zs. Zuckerindustrie, 50, pp. 982 and ro79, 1900; cf. Landolt and Börnstein's Physikalisch-Chemische Tabellen, fourth ed., p. 3 rr. 